\title{
PREDAÇÃO DE BOVINOS POR ONÇAS NO NORTE DO ESTADO DE GOIÁS
}

\author{
FRANCESCA BELEM LOPES PALMEIRA
}

\author{
Dissertação apresentada à Escola Superior de \\ Agricultura "Luiz de Queiroz", Universidade de São \\ Paulo, para obtenção do título de Mestre em Ecologia \\ de Agroecossistemas.
}

P I R A C I C A B A

Estado de São Paulo - Brasil

Novembro - 2004 


\title{
PREDAÇÃO DE BOVINOS POR ONÇAS NO NORTE DO ESTADO DE GOIÁS
}

\author{
FRANCESCA BELEM LOPES PALMEIRA
}

Bióloga

Orientador: Prof. Dr. VALDEMAR LUIZ TORNISIELO

Dissertação apresentada à Escola Superior de Agricultura "Luiz de Queiroz", Universidade de São

Paulo, para obtenção do título de Mestre em Ecologia de Agroecossistemas.

P I R A C I C A B A

Estado de São Paulo - Brasil

Novembro - 2004 


\section{Dados Internacionais de Catalogação na Publicação (CIP) DIVISÃO DE BIBLIOTECA E DOCUMENTAÇÃO - ESALQ/USP}

Palmeira, Francesca Belem Lopes

Predação de bovinos por onças no norte do Estado de Goiás / Francesca Belem Lopes

Palmeira. - - Piracicaba, 2004.

53 p. : il.

Dissertação (Mestrado) - - Escola Superior de Agricultura Luiz de Queiroz, 2004.

Bibliografia.

1. Bovino 2. Conservação biológica 3. Ecologia animal 4. Felino 5. Idade animal 6. Mortalidad animal 7. Predação 8. Propriedade rural I. Título

CDD 591.5 
Dedico essa pesquisa a toda minha família, especialmente, à minha mãe, Benvinda Belem Lopes 


\section{AGRADECIMENTOS}

Ao Fundo Mundial para a Natureza (WWF) e Ford Fundation, Idea Wild, Reserva Brasil, Programa de Apoio à Pós-Graduação (PROAP/CAPES), Benvinda Belem Lopes, Fazenda Ouro Branco, especialmente Ernesto Bilch, Fazenda Pintado, Fazenda Lagoa da Prata, Associação de Pais e Alunos Excepcionais (APAE) de São Miguel do Araguaia e Instituto Educacional Araguaia (IEA), pelo apoio concedido.

Ao Peter Gransden Crawshaw Junior, Cláudio Maluf Haddad, Luciano Martins Verdade, Valdemar Luiz Tornisielo, Cristiano Trapé Trinca, Paulo Inácio K. L. Prado, Walter Barrella, Ana Maria Trapé Trinca, Walter Trinca, Antonio Zumstein, Olga Zanini Zumstein, Kátia Maria Paschoaletto Michi de Barroz Ferraz, Carlos Alberto Vettorazzi, Saulo Delgado, Roberta de Oliveira Averna Valente, Marcelo Côrrea Alves, Carlos Piña, Anne-Sophie Bertrand e Manoel Cabral de Castro, pela contribuição intelectual.

Ao Cristiano Trapé Trinca, Rodrigo Deléo Amato, Bruna Carolina Rodrigues de Carvalho, Fernando Azzi Haddad, Bento Carlos de Arruda Neto, Rally e todos os funcionários da Fazenda Ouro Branco no período de outubro de 2002 a janeiro de 2004, pela assistência na pesquisa de campo.

Ao Normando White Peres, Elisangela da Silva, Benvinda Belem Lopes, Ana Maria Trapé Trinca, Márcia Trapé, Cristiano Trapé Trinca, Camila Câmara Pianca, Mariana Clauzet, Carla Josef, Nelson Antonio Calil Filho, Paula Daniel Fogaça, Diego Sanchez, Rômulo Fernandes Batista, Carlos Eduardo Marinelli, Abílio Gabriel Martins e Milena Ramires, pelo fornecimento de materiais e incentivo constante. 


\section{SUMÁRIO}

Página

LISTA DE FIGURAS............................................................................ vii

LISTA DE TABELAS.............................................................................. ix

RESUMO

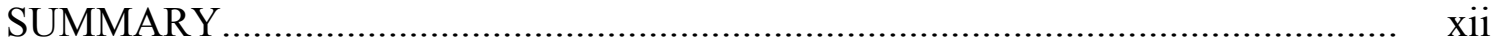

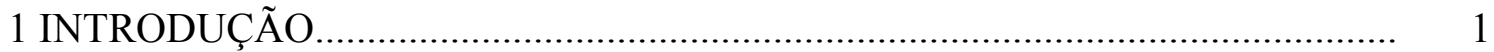

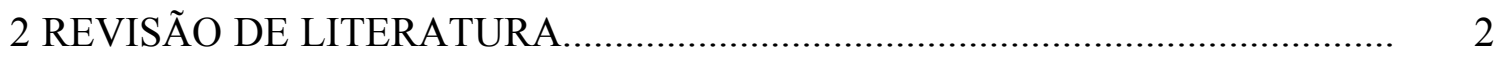

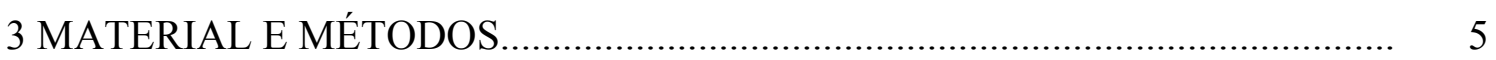

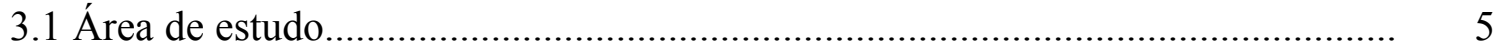

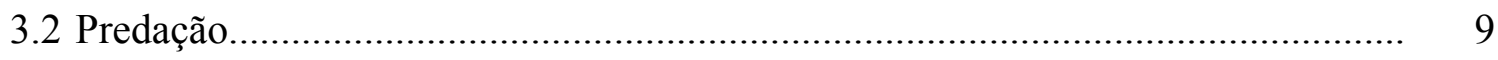

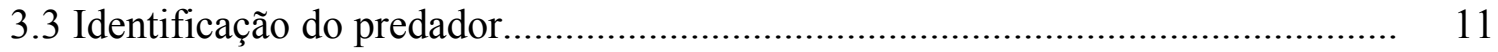

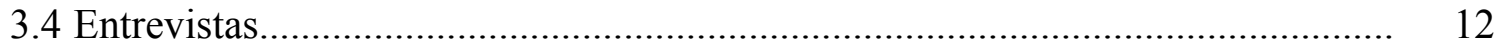

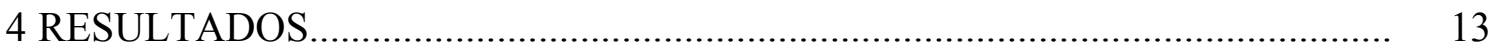

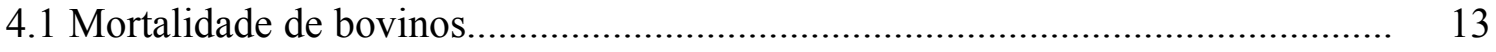

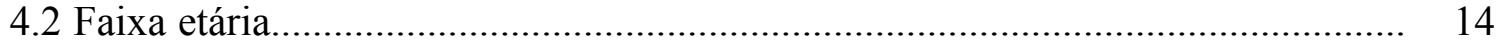

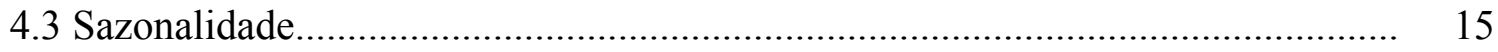

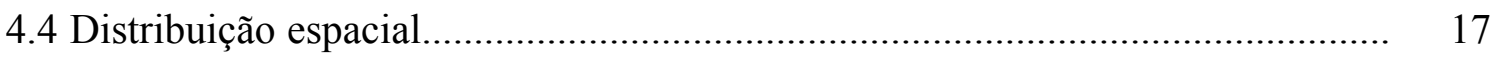

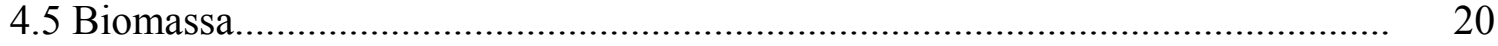

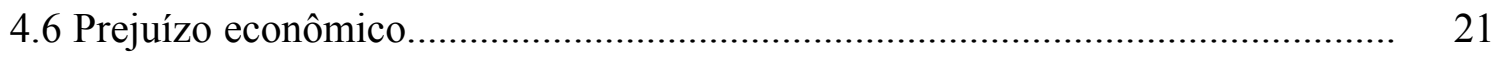

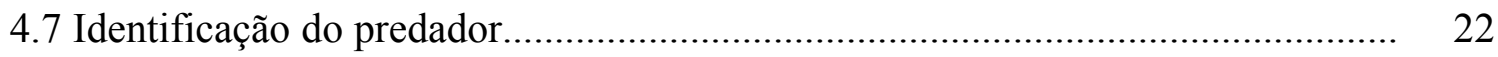

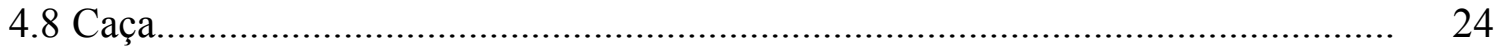

5 DISCUSSÃO 


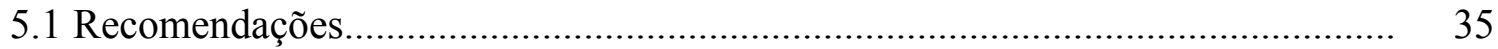

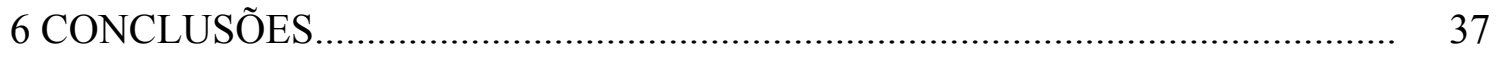

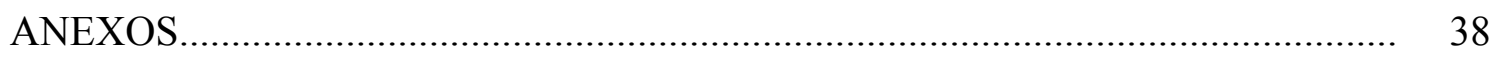

REFERÊNCIAS BIBLIOGRÁFICAS................................................................. 44 


\section{LISTA DE FIGURAS}

Página

1 Localização do Município de Bonópolis situado ao Norte do Estado

de Goiás, Centro-Oeste do Brasil............................................................................. 6

2 Fazenda Ouro Branco (20.000 ha), divida nos retiros Colina Verde (CV),

Madeireira (MD), Liberdade (LB), Zequinha (ZQ), Xodó (XD) e Sede (SD)

3 Vista parcial dos pastos situados à borda dos fragmentos florestais

na Fazenda Ouro Branco.

4 Predação por onças e outras causas, de acordo com a mortalidade total de bovinos na Fazenda Ouro Branco, no período de seis anos *Com exceção da predação, os dados de 2003 foram referentes apenas aos meses de abril, maio e junho)

5 Associação negativa $\left(\mathrm{p}<0,05 ; \mathrm{r}_{\mathrm{s}}=-0,80\right)$ da predação com a idade (meses) dos bovinos predados na Fazenda Ouro Branco, de 1998 a 2003

6 Freqüência média mensal da predação por onças e do nascimento de bezerros na Fazenda Ouro Branco, de 1998 a 2003. 
7 Distribuição espacial da predação dentro dos limites da Fazenda Ouro

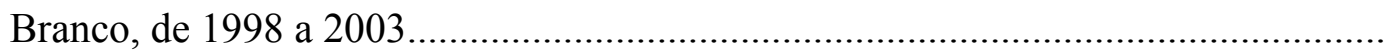

8 Predação de bezerro por onça-parda (Puma concolor) na Fazenda Ouro

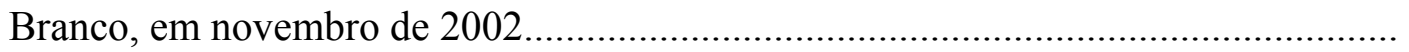

9 Predação de bezerro por onça-pintada (Panthera onca) na Fazenda Ouro Branco, em fevereiro de 2003 ............................................................................

10 Peles de onça-pintada (Panthera onca) e de onça-parda (Puma concolor), ambos machos, caçados em 2001 na Fazenda Ouro Branco.

11 Onça-pintada (Panthera onca) macho, caçada em fevereiro de 1998 na Fazenda Ouro Branco. 


\section{LISTA DE TABELAS}

Página

1 Quantidade de bovinos, número de pastos, área (ha) e tipo de manejo

por retiro na Fazenda Ouro Branco, em março de 2003

2 Ocorrência (n) da predação por onças e outras causas de acordo com a categoria de bovinos na Fazenda Ouro Branco, de 1998 a 2003 ..............................................

3 Freqüência anual da predação por onças nos retiros da Fazenda Ouro Branco......

4 Pastos (n) com predação por onças na Fazenda Ouro Branco, de 1998 a $2003 . . . . .$.

5 Estimativa da biomassa de bovinos $(\mathrm{kg})$ e da biomassa predada em $\left(\mathrm{kg} / \mathrm{km}^{2}\right)$ por retiro $\left(\mathrm{km}^{2}\right)$ na Fazenda Ouro Branco, de 1998 a 2003.

6 Biomassa média (kg) de acordo com a classe de idade (meses) de bovinos predados na Fazenda Ouro Branco, de 1998 a 2003.

7 Prejuízo econômico (R\$ e US\$) de acordo com categoria de bovinos predados por onças na Fazenda Ouro Branco, de 1998 a 2003. 
8 Predação de bovinos (n) causadas por onças-pardas (Puma concolor) e onças-pintadas (Panthera onca) nos retiros da Fazenda Ouro Branco,

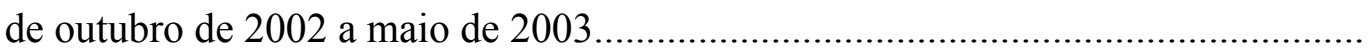

9 Predação por onças-pardas (Puma concolor) e onças-pintadas (Panthera onca) de acordo com a classe de idade (meses) dos bovinos na Fazenda Ouro Branco,

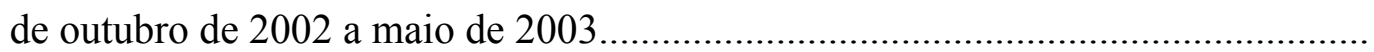

10 Onças-pardas (Puma concolor) e onças-pintadas (Panthera onca) mortas na Fazenda Ouro Branco e propriedades vizinhas (Fazenda Pintado, Fazendo Rio Vermelho e Fazenda Lagoa da Prata), de 1998 a 2003. 


\title{
PREDAÇÃO DE BOVINOS POR ONÇAS NO NORTE DO ESTADO DE GOIÁS
}

\author{
Autora: FRANCESCA BELEM LOPES PALMEIRA \\ Orientador: Prof. Dr. VALDEMAR LUIZ TORNISIELO
}

\section{RESUMO}

A predação de bovinos (Bos sp.) por onças-pardas (Puma concolor) e onçaspintadas (Panthera onca) foi registrada durante seis anos em uma propriedade rural no Norte do Estado de Goiás, Centro-Oeste do Brasil. A pesquisa teve os objetivos de verificar: (1) quanto bovinos são predados por onças; (2) qual a faixa etária mais predada; (3) se existe sazonalidade na ocorrência da predação e (4) qual sua distribuição espacial em relação aos elementos constituintes da paisagem. A predação foi registrada e quantificada com auxílio dos retireiros e responsáveis pelo manejo dos bovinos, que forneceram em uma ficha o nome do observador, data, retiro, número do pasto, causa da morte, idade e sexo. A predação representou $21,7 \%(n=309)$ da mortalidade total de bovinos. Os bovinos predados representaram uma biomassa média anual de $63,8 \mathrm{~kg} / \mathrm{km}^{2}$, que foi equivalente a $0,4 \%$ do estoque médio anual de bovinos. A categoria mais predada foi o bezerro. A predação se associou fortemente à idade dos animais predados, ocorrendo mais com bezerros de até 2 meses e diminuindo gradativamente com o aumento da idade. A predação foi influenciada pela categoria de bovinos (idade e sexo), local e período de nascimentos. Ficou evidente que a predação foi diferente espacial e temporalmente. Dessa forma, um conjunto de medidas preventivas foi sugerido para reduzir a predação de bovinos e garantir a conservação das onças. 


\title{
LIVESTOCK PREDATION BY BIG CATS IN NORTH STATE OF THE GOIÁS
}

\author{
Author: FRANCESCA BELEM LOPES PALMEIRA \\ Adviser: Prof. Dr. VALDEMAR LUIZ TORNISIELO
}

\section{SUMMARY}

Data on cattle predation by pumas (Puma concolor) and jaguars (Panthera onca) has been recorded for six years in a farm in Northern Goiás, Mid-Western Brazil. This research's main objectives were to determine: (1) the actual proportion of cattle killed by big cats; (2) whether there was a certain age class targeted by those predators; (3) whether the predation fluctuated along the year and (4) the spatial distribution of cattle predation. Data were recorded by employees and cattle managers using forms with the following information (observer's name, date, id numbers, cause of mortality, age and sex). Predation represented 21,7\% $(n=309)$ of the overall cattle mortality. In biomass, kills represented $0,4 \%$ of the farm' annual stock with $63,8 \mathrm{~kg} / \mathrm{km}^{2}$. Predation was strongly correlated with cattle's age with most attacks occurring on calves younger than 2 months old then gradually decreasing the animals get older. Predation was mainly associated with cattle's age class and location along with the time of the births it occurred. It clearly appeared that cattle predation varied spatially and temporally. We recommended several preventive techniques to be used in order to limit cattle predation in rural farming contexts so as to reduce the conflict between villagers and large felids and thus enhance the last big cats' conservation. 


\section{INTRODUÇÃO}

Com o desenvolvimento da pecuária, o desmatamento aumentou e áreas naturais foram substituídas por extensas pastagens, especialmente no Cerrado brasileiro. Conseqüentemente, as onças-pintadas (Panthera onca) e as onças-pardas (Puma concolor) passaram a coexistir com rebanhos domésticos, que são suas presas potenciais. Os proprietários freqüentemente se baseiam na predação de criações domésticas para justificar a perseguição às onças (Quigley \& Crawshaw, 1992; Silva, 1994), que se encontram ameaçadas em várias localidades das regiões Sul e Centro-Oeste do Brasil (Quigley et al., 1988; Fonseca et al., 1994; Crawshaw, 1995). Dessa forma, o controle exercido por criadores, como forma de evitar a predação de criações domésticas, vem se tornando o principal fator de desaparecimento dos grandes felinos, especialmente fora de áreas legalmente protegidas (Linnell et al., 1999; Jackson \& Nowell, 1996; Nowell \& Jackson, 1996). Apesar do intenso conflito, poucos dados demonstraram perdas econômicas resultantes dessa predação. Quantificar a predação é fundamental para traçar planos de manejo direcionados a cada fazenda, a fím de diminuir os prejuízos e aumentar as chances de conservação das onças. Nesse contexto, esta pesquisa teve por objetivo responder às seguintes perguntas:

1) quantos bovinos são predados por onças em uma fazenda no Norte do Estado de Goiás, Centro-Oeste do Brasil?

2) qual é a faixa etária dos bovinos que mais sofre predação por onças?

3) existe sazonalidade na ocorrência da predação por onças? Em caso afirmativo, qual é o período em que mais ocorre?

4) qual é a distribuição espacial da predação em relação aos elementos constituintes da paisagem? 


\section{REVISÃO DE LITERATURA}

Os conflitos entre proprietários de criações domésticas e predadores provavelmente tiveram início desde que os primeiros animais foram domesticados pelos seres humanos há cerca de 9.000 anos (Nowell \& Jackson, 1996). Por terem perdido seu comportamento anti-predador, os animais domésticos são mais facilmente perseguidos e atacados por predadores do que as presas silvestres de tamanhos similares (Jackson \& Nowell, 1996; Nowell \& Jackson, 1996; Linnell et al., 1999). Desde então, os leões (Panthera leo), os leopardos (Panthera pardus), os tigres (Panthera tigris), os leopardos das neves (Panthera uncia), entre outros grandes felinos, são considerados os maiores responsáveis pela predação de criações domésticas em diferentes partes do mundo (Anderson, 1981; Schaller et al., 1988; Seidensticker et al., 1993; Mizutani, 1993; Oli et al., 1994; Patterson et al., 2004). No continente americano, as onças-pintadas (Panthera onca) e as onças-pardas (Puma concolor) têm sido as principais predadoras de animais domésticos em muitas propriedades rurais (Schaller, 1983; Ackerman et al., 1984; Rabinowitz, 1986; Yáñez et al., 1986; Guix, 1992; Hoogesteijn et al., 1993; Crawshaw, 1995; Perovic \& Herrán, 1998; Mazzolli et al., 2002; Rau \& Jiménez, 2002).

No Brasil, os primeiros registros de predação por onças ocorreram em 1946, durante expedições científicas, como a Expedição Roncador-Xingu-Tapajós, na região do rio das Mortes, Estado de Mato Grosso, onde várias mulas foram predadas por uma onça-pintada (Sick, 1997). Na mesma ocasião, os irmãos indigenistas Villas-Boas registraram um fato semelhante com seus animais de transporte. Poucos anos depois, em outra expedição na mesma região, 14 burros foram abatidos por uma onça-pintada (Carvalho et al., 1949). Esses relatos sugerem que a predação por onças ocorreu mesmo quando não havia atividade pecuária no local e a quantidade de área desmatada era 
reduzida. Recentemente, a predação de animais domésticos por onças continua ocorrendo e se tornou foco de diversas pesquisas desenvolvidas nos Estados de Minas Gerais (Rylands et al., 1995), Santa Catarina (Mazzolli, 1993; Mazzolli et al., 1996; Mazzolli et al., 2002), Paraná (Manzatti, 1999; Conforti \& Azevedo, 2003), Mato Grosso (Marques, 1999), Mato Grosso do Sul (Zirmmermann, 2000), entre outros.

As onças possuem grande plasticidade comportamental para se adaptarem a variadas condições ambientais nas diferentes áreas de suas distribuições (Rabinowitz \& Nottingham, 1986; Iriarte et al., 1990; Crawshaw, 1992). São consideradas espécies oportunistas por se utilizarem de uma extensa variedade de presas silvestres (Rabinowitz \& Nottingham, 1986; Yañez et al., 1986; Emmons, 1987; Iriarte et al., 1990; Guix, 1992; Chinchilla, 1997; Guix, 1997; Taber et al., 1997; Frankilin et al., 1999; Núñez et al., 2000; Garla et al., 2001; Novack, 2003; Polisar et al., 2003; Scognamillo et al., 2003).

Um dos fatores importantes que influencia o comportamento alimentar das onças é a disponibilidade de presas no ambiente (Mondolfi \& Hoogesteijn, 1986; Rabinowitz \& Nottingham, 1986; Emmons, 1987). Emmons (1987), no Peru, e Rabinowitz \& Nottingham (1986), em Belize, constataram que a freqüência das diferentes espécies de presas silvestres encontradas nas amostras fecais dos felinos estava relacionada à dinâmica e à abundância das mesmas no ambiente. No Pantanal, o bovino foi o principal item alimentar das onças e também representou a maior biomassa de alimento disponível (Crawshaw \& Quigley, 1984).

O fator "cultural" também influencia o hábito alimentar dos felinos (Jackson \& Nowell, 1996). Os predadores apresentam traços comportamentais individuais e quando predam criações domésticas desenvolvem um comportamento de caça especializado (Linnell et al., 1999). Crawshaw \& Quigley (1984) verificaram que as preferências alimentares das onças-pintadas variaram individualmente e alguns animais utilizaram algumas espécies-presas com maior freqüência, sugerindo que essa predileção seja, em parte, influenciada pelo período de aprendizado anterior à independência nutricional dos filhotes. Rabinowitz (1986) observou que a única fêmea predadora de rebanhos domésticos apresentava um padrão de comportamento mais diurno que os outros 
indivíduos, indicando uma flexibilidade no padrão de comportamento baseado naquele das espécies presas.

A predação pode ser influenciada pelas características biológicas do predador em questão. Entre os carnívoros solitários, a maioria das predações registradas foi causada por machos adultos (Linnell et al., 1999) e sub-adultos (Rabinowitz, 1986). Em muitos casos, os predadores de criações podem ser animais feridos, doentes e velhos (Jackson \& Nowell, 1996). Rabinowitz (1986) examinou dezenas de carcaças de onças-pintadas e verificou que a maioria dos animais predadores apresentava seqüelas e cicatrizes de ferimentos na cabeça e no corpo, enquanto que os não-predadores de rebanhos não apresentavam nenhuma injúria.

Têm sido diversas as causas que predispõem os predadores silvestres a abater criações domésticas (Hoogesteijn et al., 1993; Jackson \& Nowell, 1996; Linnell et al., 1999; Polisar et al., 2003). No caso dos leopardos das neves, a taxa de predação variou com a localidade, densidade de predadores, habitat e padrões do manejo de criações domésticas (Jackson \& Wangchuk, 2001). A predação de animais domésticos por onçaspardas e onças-pintadas tem sido influenciada por fatores como comportamento inato e aprendido, saúde e "status" individual, divisão do espaço e recursos entre as espécies, práticas de manejo dos bovinos, abundância e distribuição de presas naturais (Polisar et al., 2003), condições do tempo, hora do dia, características físicas e bióticas do terreno e condições físicas do predador (Mazzolli et al., 2002). 


\section{MATERIAL E MÉTODOS}

\section{1 Área de estudo}

A pesquisa foi realizada na Fazenda Ouro Branco, município de Bonópolis, Norte do Estado de Goiás, Centro-Oeste do Brasil (Figura 1). Bonópolis possui cerca de $1.634,50 \mathrm{~km}^{2}$ e está localizado entre as coordenadas $13^{\circ} 38^{\prime} 11^{\prime \prime} \mathrm{S}$ e $49^{\circ} 48^{\prime} 37^{\prime \prime} \mathrm{W}$, no trecho do Médio Araguaia que faz parte da sub-bacia hidrográfica do rio Araguaia e da região hidrográfica do Tocantins (IBGE, 2002). O clima é quente semi-úmido, com quatro a cinco meses secos. Possui uma temperatura média de $25^{\circ} \mathrm{C}$ e uma altitude média de 290 m (IBGE, 2002). O solo predominante é classificado como latossolo vermelho-amarelo (IBGE, 2001). Embora faça parte do bioma Cerrado, localiza-se na área de transição entre o Cerrado e a Floresta Amazônica (Dinerstein et al., 1995).

O Cerrado é a segunda maior ecorregião do Brasil, depois da Floresta Amazônica. Está incluído entre os "hotspots" porque sua diversidade vegetal é uma das mais ricas de todas as savanas tropicais com altos níveis de endemismo (Mittermeier et al., 1999). O mosaico de vegetação é composto por agriculturas e pastagens permanentes dominantes, seguido por florestas de galeria, florestas estacionais decíduas densas e savanas arbustivas (Miranda \& Guimarães, 2002). Ocorrem importantes espécies vegetais como aroeira (Anacardiaceae), cedro (Meliaceae), ipê (Tabebuia sp.: Bignoniaceae), pequi (Caryocar brasiliense: Caryocaraceae), peroba (Aspidosperma sp.: Apocynaceae), sucupira (Leguminosae-Papilionoideae), entre outras. O Cerrado foi considerado uma das áreas mais importantes e prioritárias para a pesquisa e para a conservação da onça-pintada, pela falta de conhecimento a respeito da distribuição geográfica e do "status" da população (Sanderson et al., 1999). 
O Município de Bonópolis possui uma população humana de aproximadamente 2.598 habitantes, 1.131 na área urbana e 1.467 na área rural, com uma densidade demográfica média de 1,63 habitantes $/ \mathrm{km}^{2}$ (IBGE, 2000). Começou a se formar no final da década de 60, com a chegada de madeireiros. Faz parte da micro-região de Porangatu, município do qual se emancipou em 1995. Também faz divisa com São Miguel do Araguaia, que é muito visitado durante a temporada de pesca, especialmente em julho. Atualmente, a principal atividade econômica em Bonópolis é a cultura de soja (Glycine max) e a pecuária extensiva, com cerca de 90.000 bovinos (IBGE, 1997).

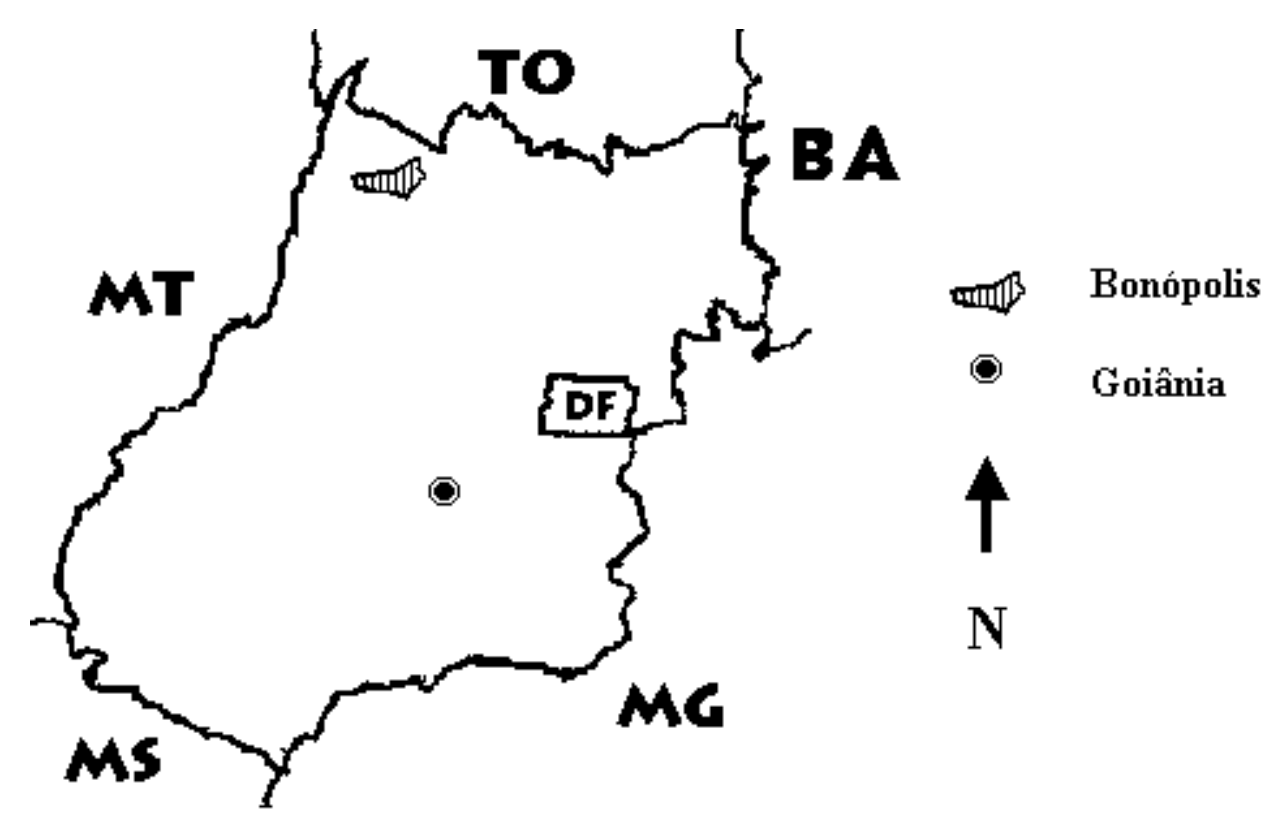

Figura 1 - Localização do Município de Bonópolis, situado ao Norte do Estado de Goiás, Centro-Oeste do Brasil

A Fazenda Ouro Branco possui cerca de 14,5\% dos bovinos estimados para o Município. Ela compreende uma área de aproximadamente 20.000 ha divididos em seis retiros, denominados de Sede (SD), Colina Verde (CV), Liberdade (LB), Zequinha (ZQ), Xodó (XD) e Madeireira (MD) (Figura 2). 


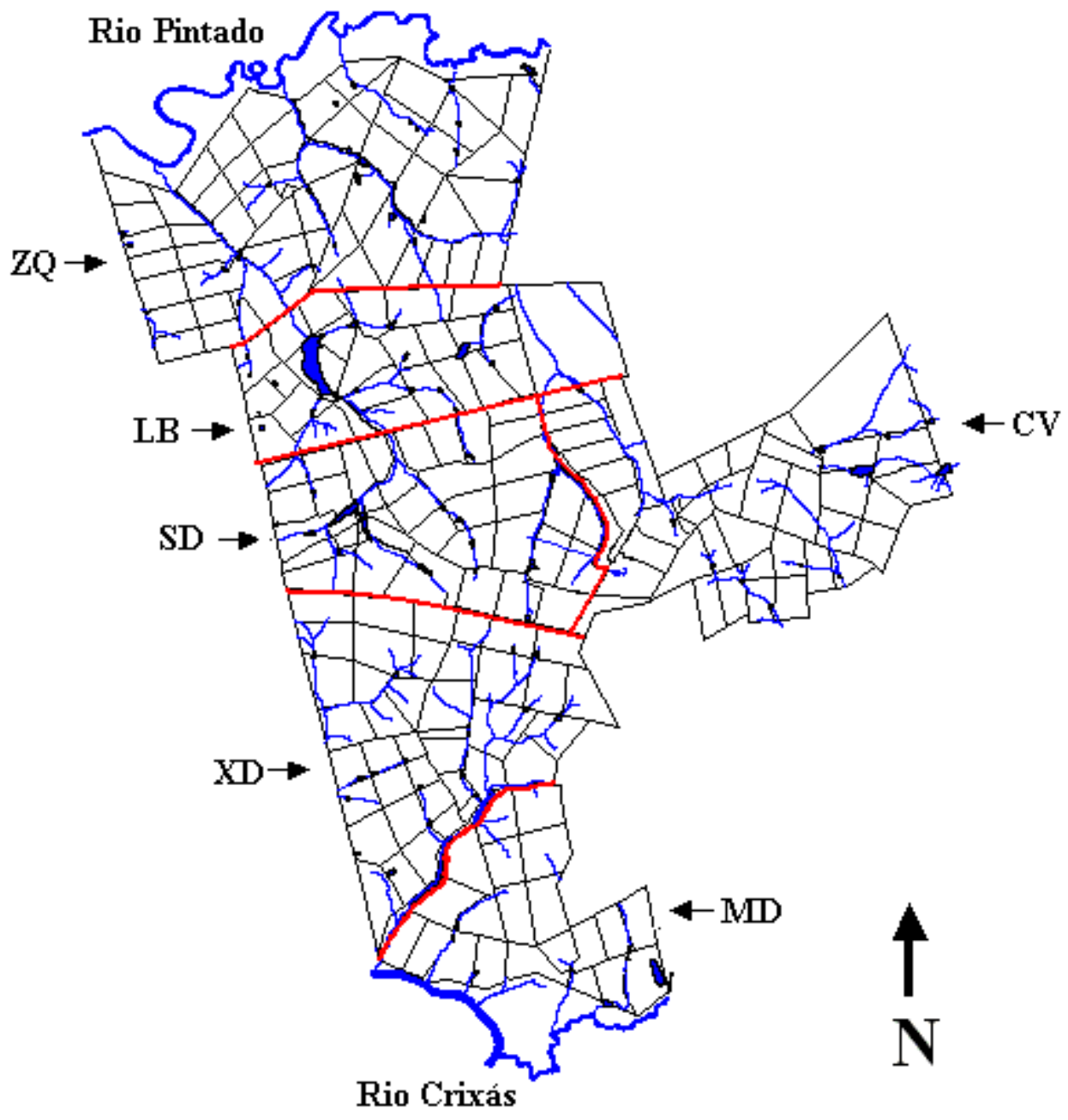

Figura 2 - Fazenda Ouro Branco (20.000 ha), dividida nos retiros Colina Verde (CV), Madeireira (MD), Liberdade (LB), Zequinha (ZQ), Xodó (XD) e Sede (SD) (Adaptado de Antonio Zumstein) 
Os retiros são idealizados para descentralizar e facilitar as operações e manejo. Cada retiro possui um manejo diferenciado e alguns fatores são número de bovinos, área (ha), faixa etária dos animais, tipo de pasto, qualidade de bovinos (raça) e sexo. $\mathrm{Na}$ região, são mantidos cerca de dois indivíduos/ha de pasto. As raças de bovinos predominantes são nelore, fleckvieh e cruzado de ambos. Foram identificados cinco tipos de manejo: inseminação artificial, recria, primípara, descarte e diversificado que foi uma mistura de cada um. A Tabela 1 demostra os diferentes manejos nos retiros da Fazenda Ouro Branco em março de 2003.

Tabela 1. Quantidade de bovinos, número de pastos, área (ha) e tipo de manejo por retiro na Fazenda Ouro Branco, em março de 2003

\begin{tabular}{lrrrl}
\hline Retiro & Bovinos (n) & Pasto (n) & Área (ha) & Tipo de manejo \\
Colina Verde & 2.800 & 39 & 2.458 & Primípara \\
Madeireira & 1.587 & 21 & 1.587 & $90 \%$ Descarte \\
Liberdade & 1.650 & 26 & 1.669 & Diversificado \\
Zequinha & 2.480 & 54 & 3.446 & Inseminação e Recria \\
Xodó & 1.188 & 39 & 2.420 & Recria de touros \\
Sede & 1.900 & 39 & 2.550 & Inseminação \\
Total & 13.098 & 218 & 14.130 & --- \\
\hline
\end{tabular}

O restante da área é composto por reservas legais, rios, represas e estradas. As reservas mais importantes e consideráveis são as matas ciliares de três importantes rios, que estão localizados nos limites da Fazenda. No limite Norte localiza-se o rio Pintado e no limite Sul está a confluência dos rios Gregório e Crixás (Figura 2). Os rios Pintado e Gregório desembocam no rio Crixás, que é um dos principais afluentes à margem direita do rio Araguaia. No geral, a Fazenda possui inúmeros pastos situados na borda de fragmentos florestais de diferentes áreas (ha) em todos os retiros (Figura 3). 


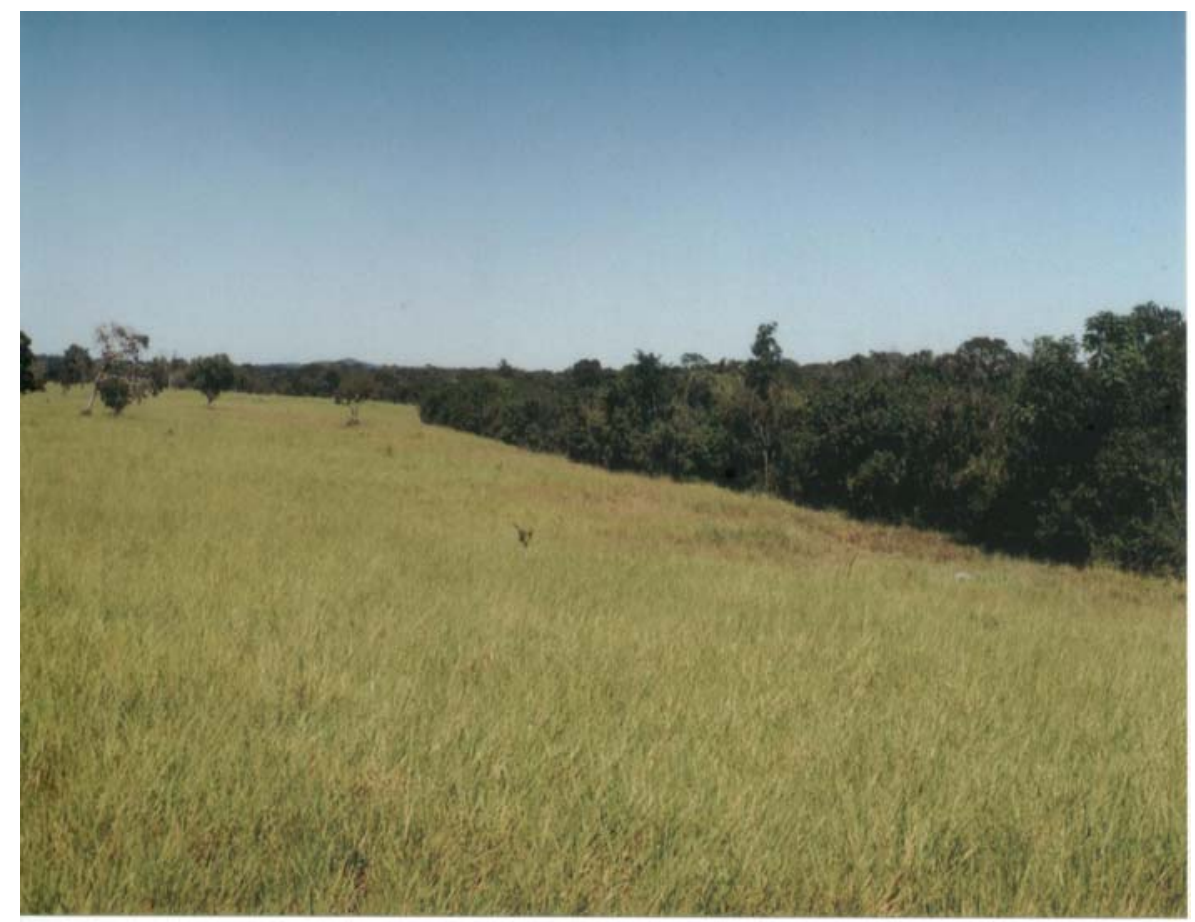

Figura 3 - Vista parcial dos pastos situados à borda dos fragmentos florestais na Fazenda Ouro Branco

\subsection{Predação}

Para levantar a predação por onças, foram utilizadas as fichas de morte de bovinos preenchidas por responsáveis pelo manejo de cada retiro (retireiros) para registrar a mortalidade geral do rebanho (Anexo A). Quando a causa da morte foi atribuída a predação por onças, foram anotados, data, retiro, número do pasto, idade e sexo (Anexo B).

Os dados dessas fichas são recolhidos pelo capataz e repassados para o secretário da Fazenda, que reune mensalmente as informações de todos os retiros no Boletim Pecuário (Anexo C). Este Boletim tem o objetivo geral de organizar e contabilizar o estoque de bovinos (entradas e saídas) para prestação de contas ao gerente e proprietários da Fazenda, incluindo as empresas associadas no Estado de São Paulo. No Boletim, os bovinos foram divididos em 17 categorias, estabelecidas de acordo com as 
classes de idade e sexo (Anexo C). Para simplificar as análises na presente pesquisa, os bovinos foram agrupados em cinco categorias: bezerros e bezerras (0-12 meses), novilhas e garrotes (12-24 meses), vacas, bois e touros ( $>24$ meses). Outros pesquisadores dividiram os bovinos em categorias, que representam diferentes níveis de vulnerabilidade para os predadores. Crawshaw \& Quigley (1984) dividiram os bovinos em quatro categorias, como bezerros (até dois anos de idade), vacas, bois e touros. Polisar et al. (2003) dividiram a idade dos bovinos em sete categorias, bezerros de 0-3 meses, bezerros de 3-6 meses, bezerros de 6-9 meses, bezerros de 10-24 meses, vacas e bois ou touros.

Para levantar informações sobre nascimentos, mortes, saldo anterior, saldo atual e valor unitário (R\$) de todas as categorias de bovinos, foi utilizado o Boletim Pecuário mensal de janeiro de 1998 a dezembro de 2003. O valor econômico em reais (R\$) de cada animal predado foi convertido em unidade de dólares americanos (US\$) $(\mathrm{R} \$ 1,00=$ US\$ 3,15 em julho de 2004) para se estimar o prejuízo econômico resultante da predação.

Para se estimar a biomassa, foram utilizadas as informações de massa $(\mathrm{kg})$ de cada categoria de bovino nas notas de rodapé dos Boletins (Anexo C). A biomassa média e o valor econômico também foram estimados para cada categoria dos bovinos. Para se estimar a biomassa $\left(\mathrm{kg} / \mathrm{km}^{2}\right)$, o peso médio do bovino $(175 \mathrm{~kg})$ foi multiplicado pelo número total de indivíduos e dividido pela área $\left(\mathrm{km}^{2}\right)$, como utilizado por Schaller (1983), Crawshaw \& Quigley (1984) e Polisar et al. (2003).

Os índices de chuva $(\mathrm{mm})$ também foram levantados pelos retireiros e repassados à administração da Fazenda (Anexo D). Para comparar os índices de chuva com os nascimentos de bezerros e com as predações por onças, foram utilizados os dados da precipitação (mm) mensal de janeiro de 1998 a dezembro de 2003, assim como os Boletins Pecuário.

Devido à não-normalidade dos dados, foi realizado teste não-paramétrico de correlação de Spearman (rs) (Centeno, 1999, Ayres et al., 2000), para avaliar a existência de associação $(p<0,05)$ entre: predação com a idade (meses) de bovinos predados, predação com os nascimentos mensais de bezerros, precipitação (mm) mensal com a 
predação e precipitação $(\mathrm{mm})$ mensal com os nascimentos. Também foi utilizado o teste Qui-quadrado $\left(\mathrm{x}^{2}\right)$, para verificar a existência de diferenças significativas $(\mathrm{p}<0,05)$ entre sexos dos bovinos predados (Centeno, 1999, Ayres et al., 2000).

Para se identificar as áreas de maior incidência de ataques, os pastos onde ocorreram as predações foram demarcados com auxílio do Sistema de Posicionamento Global (GPS) 12 satélites e georeferenciados em um mapa da área. Foram verificadas quais as distâncias entre os locais onde ocorreram os ataques e as reservas florestais das propriedades, como proposto por Mähler (2000). O número de predações nas bordas das reservas florestais foi calculado para verificar a freqüência da predação à medida que aumenta a distância entre os pastos e as reservas.

\subsection{Identificação do predador}

A distinção entre os ataques de onças-pardas e onças-pintadas não foi considerada pelos retireiros. Ela apenas foi possível durante o período da pesquisa de campo, de outubro de 2002 a maio de 2003. Sempre que ocorreu predação com a

presença do animal abatido ou ferido, houve o deslocamento até o local. A carcaça foi vistoriada para determinar se a causa mortis foi por predação ou não. A idade e o sexo foram verificados. Foram procuradas lesões externas e internas que pudessem ser causadas por mordidas e arranhões de onças, especialmente no crânio, pescoço e membros, a fim de se distinguir o predador em questão (Anexo E).

Os ataques causados por onças-pintadas resultam na quebra ou no deslocamento das vértebras cervicais, decorrentes ou do impacto na queda do animal ou de mordida na base do crânio ou na nuca. Normalmente, a onça-pintada começa a se alimentar pela cabeça, pescoço e região peitoral, sendo comum deixar as partes posteriores intactas (Mondolfi \& Hoogesteijn, 1986; Schaller \& Crawshaw, 1980; Guix, 1992; Hoogesteijn et al., 1993). Em contraste, as onças-pardas matam a presa por sufocamento, com mordida na garganta, deixando também marcas das garras nos ombros e nas costas das presas. Sua alimentação se inicia após as costelas e na musculatura das patas posteriores, quase sempre pela porção ventral (CENAP, 1998). 


\subsection{Entrevistas}

No início de outubro de 2002, foram realizados os primeiros contatos com os proprietários e responsáveis pelo manejo das criações domésticas, além dos preparativos para a pesquisa de campo. Tais preparativos incluíram a familiarização com a população local e a escolha das áreas que foram regularmente amostradas. As atividades de campo também compreenderam a aplicação de entrevistas informais e a busca exaustiva de carcaças predadas e outras evidências, que pudessem confirmar a ocorrência de onças na área. Para melhor compreender o funcionamento e a dinâmica de trabalho na Fazenda Ouro Branco, a rotina de manejo dos bovinos, desde inseminação artificial, nascimento, desmama, alimentação, vacinação, marcação com carimbo, embarque e abate, foi acompanhada e verificada regularmente.

Foram realizadas diversas entrevistas informais (sem questionário) com os responsáveis pelo manejo dos bovinos e demais funcionários da Fazenda Ouro Branco, Fazenda Pintado e Fazenda Lagoa da Prata. Os informantes relataram sua percepção e atitude durante as conversas no trabalho, refeições, festas e/ou comemorações, caronas para a cidade, na padaria, no posto de gasolina e na escola. Sempre que possível, as informações sobre a mortalidade de onças causada pela caça ilegal também foram registradas, como sexo e peso $(\mathrm{kg})$ aproximado do animal, local, data, tipo e motivo da caçada. Como a pesquisa teve grande repercussão entre a população rural e urbana nos municípios de Bonópolis e São Miguel do Araguaia, diversos locais foram favoráveis ao levantamento de informações e à observação da atitude da população em relação à presença de onças. O método de entrevistas e a aplicação de questionários têm sido uma importante ferramenta para quantificar as predações causadas pela fauna silvestre. No Brasil, diversos pesquisadores também utilizaram questionários e entrevistas para quantificar as predações causadas por onças (Mazzolli et al., 1996; Manzatti, 1999; Zimmermann, 2000, Mazzolli et al., 2002; Conforti \& Azevedo, 2003). 


\section{RESULTADOS}

\subsection{Mortalidade de bovinos}

A mortalidade de bovinos foi dividida em predação por onças e outras causas. A predação registrada foi, exclusivamente, causada por onças. A mortalidade por outras causas incluíu diversas doenças, raiva (Lyssavirus sp.) transmitida pelo morcego vampiro (Diphylla sp.), desnutrição, ingestão de erva tóxica, queda de raio, acidentes ocorridos durante a vacinação e monta, complicação no parto, acidentes ofídicos (Crotalus sp. e Bothrops sp.), injúrias e desaparecimentos.

A predação foi menor $(n=309,21,7 \%)$ do que as perdas por outras causas acumuladas $(\mathrm{n}=1.116,78,3 \%)$ no período de seis anos. A Figura 4 demonstra a freqüência da predação e as outras causas, em relação à mortalidade total de bovinos.

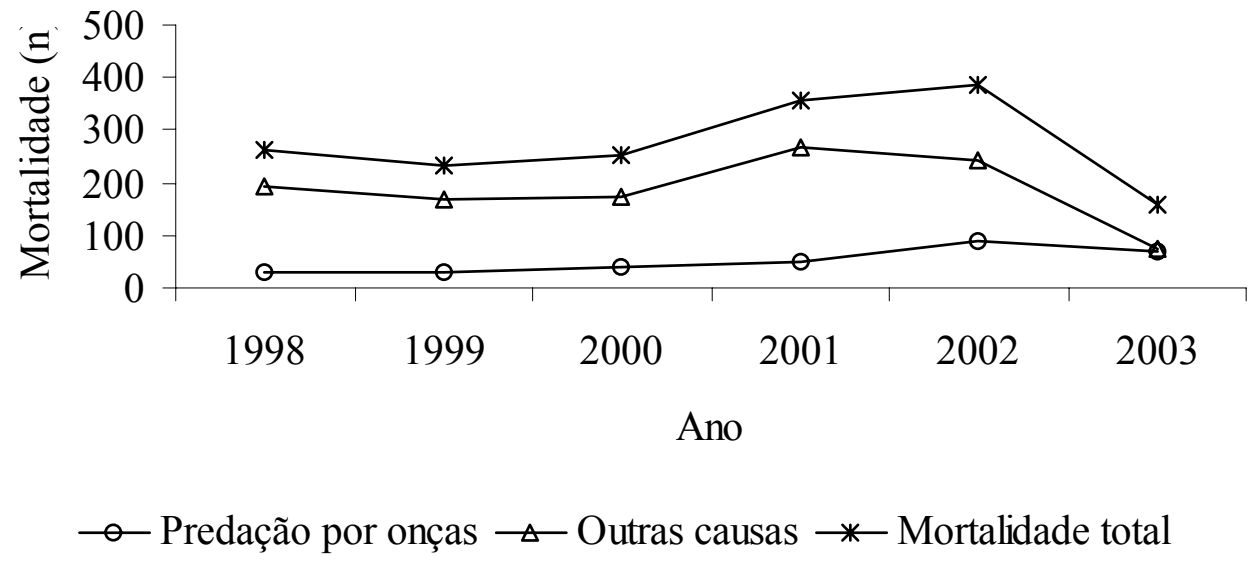

Figura 4 - Predação por onças e outras causas, de acordo com a mortalidade total de bovinos na Fazenda Ouro Branco, no período de seis anos. *Com exceção da predação, os dados de 2003 foram referentes apenas a abril, maio e junho 
A predação média anual foi cerca de $51,5 \pm 18,4$, equivalente a $0,4 \%$ do estoque médio anual de bovinos $(12.538 \pm 2.679)$.

\subsection{Faixa etária}

A freqüência de predação e outras causas foi diferente de acordo com a categoria dos bovinos (Tabela 2). A predação ocorreu apenas com os bezerros, raramente, ocorreu com as vacas e foi ausente com os bois e touros. A mortalidade por outras causas foi representada pelos bezerros, seguido pelas vacas, novilhas ou garrotes, bois e touros. As bezerras e bezerros $(54,7 \%, \mathrm{n}=778)$ foi a categoria mais vulnerável à todas as causas de mortalidade (Tabela 2).

Tabela 2. Ocorrência (n) da predação por onças e outras causas de mortalidade de acordo com a categoria de bovinos na Fazenda Ouro Branco, de 1998 a 2003

\begin{tabular}{lrrrr}
\hline Categoria de bovinos & Predação & Outras causas & Total (n) & $\%$ \\
Bezerra/Bezerro & 306 & 472 & 778 & 54,7 \\
Novilha/Garrote & 0 & 228 & 228 & 16,0 \\
Vaca & 3 & 386 & 389 & 27,3 \\
Boi & 0 & 15 & 15 & 1,0 \\
Touro & 0 & 15 & 15 & 1,0 \\
Total & 309 & 1.116 & 1.425 & 100,0 \\
\hline
\end{tabular}

A predação por onças teve uma forte associação negativa com a idade (meses) dos animais predados $\left(\mathrm{p}<0.05 ; \mathrm{r}_{\mathrm{s}}=-0,80\right)$. Foi mais freqüente em bezerros recémnascidos (0-2 meses) e diminuiu gradativamente de acordo com o aumento dos meses. Da desmama (7-8 meses) até um ano de idade (12 meses), a predação foi reduzida quase pela metade e no segundo ano (12-24 meses) esteve ausente. Os animais adultos $(>24$ meses) raramente foram predados (Figura 5). 


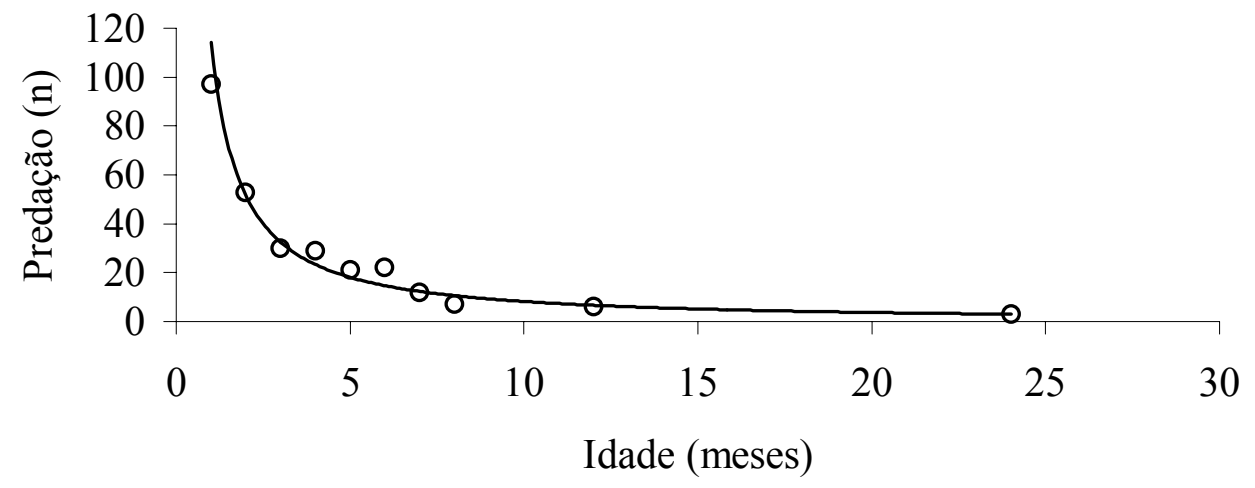

Figura 5 - Associação negativa $(\mathrm{p}<0,05 ; \mathrm{rs}=-0,80)$ da predação com a idade (meses) de bovinos predados na Fazenda Ouro Branco, de 1998 a 2003

A predação média de bezerros foi cerca de $51 \pm 23$, equivalente a $1,2 \%$ da média de nascimentos $(4.296 \pm 958)$. A razão sexual dos nascimentos de bezerros foi aproximadamente $1: 1$ entre machos $(50,1 \%)$ e fêmeas $(49,9 \%)$. Apesar disso, a razão sexual dos predados foi diferente da razão sexual dos nascidos, sendo os machos ( $\mathrm{n}=183$, $59,2 \%)$ mais predados do que as fêmeas $(\mathrm{n}=126,40,8 \%)\left(\mathrm{x}^{2}=10,51, \mathrm{gl}=1, \mathrm{p}<0,01\right)$.

\subsection{Sazonalidade}

A predação não teve associação direta com o nascimento de bezerros $(p>0,05)$, ao se comparar os dados agrupados de 1998 a 2003 e separadamente a cada ano. Contudo, os meses de nascimentos foram bem definidos e influenciaram as predações. A predação aumentou (de outubro a maio) após os meses de mais nascimentos (de setembro a dezembro) no período de seis anos (Figura 6). A predação diminuiu (de junho a setembro) somente um mês depois que os nascimentos se reduziram consideravelmente (de maio a julho) (Figura 6). 


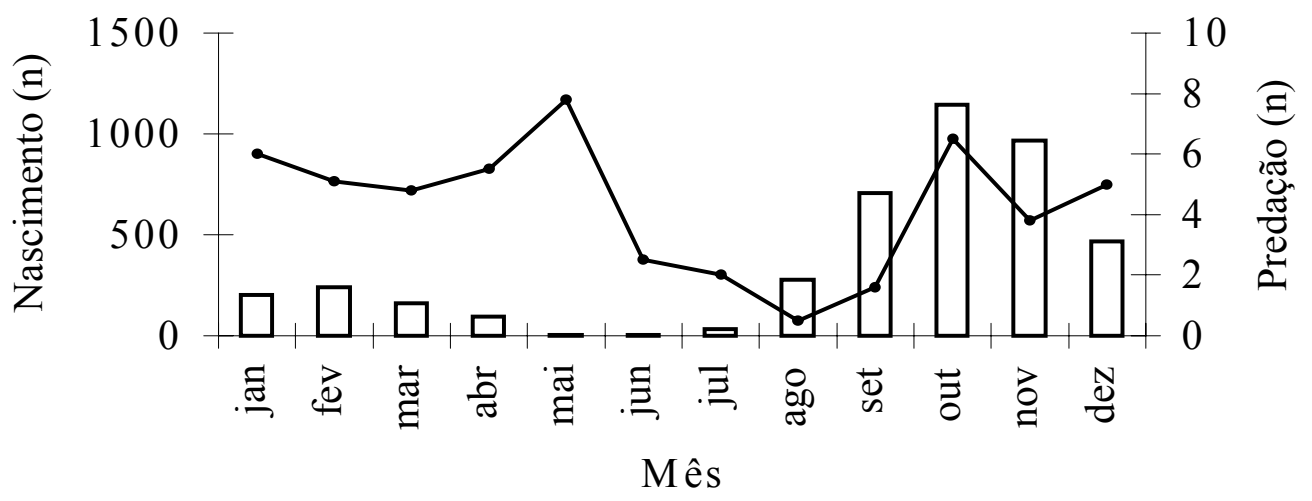

$\square$ Nascimento $\longrightarrow$ Predação

Figura 6 - Freqüência média mensal da predação por onças e do nascimento de bezerros na Fazenda Ouro Branco, de 1998 a 2003

Para facilitar as operações na Fazenda Ouro Branco, o manejo de bovinos foi diferente durante a estação seca (de maio a setembro) e a estação chuvosa (de outubro a abril). A precipitação mensal variou de 0 a $826 \mathrm{~mm}$. Os meses de junho a agosto se caracterizaram pela estiagem total e os meses com maior precipitação foram de novembro a janeiro, no período de seis anos.

A freqüência de nascimentos foi diferente durante a estação seca e a estação chuvosa. As predações foram proporcionais aos nascimentos em cada estação. Na estação seca (de maio a setembro), ocorreram poucos nascimentos ( $\mathrm{n}=6.135,23,8 \%$ ) e predações ( $\mathrm{n}=87,28,2 \%$ ). Na estação chuvosa (de outubro a abril), ocorreu a maior parte dos nascimentos ( $\mathrm{n}=19.644,76,2 \%)$ e das predações ( $\mathrm{n}=222,71,8 \%)$.

Os nascimentos de bezerros tiveram associação com a precipitação $(\mathrm{mm})$ mensal $(\mathrm{p}<0,01 ; \mathrm{r}=0,43)$, de 1998 a 2003. A predação não teve associação $(p>0,05)$ com a precipitação (mm) mensal, ao se comparar os dados agrupados de 1998 a 2003 . No entanto, analisando-se separadamente, foi encontrada forte associação com a precipitação $(\mathrm{mm})$ em $1998(\mathrm{p}<0,01 ; \mathrm{r} s=0,78)$, em $2000\left(\mathrm{p}<0,05 ; \mathrm{rs}_{\mathrm{s}}=0,58\right)$ e em 2002 $(\mathrm{p}<0,05 ; \mathrm{rs}=0,61)$. 


\subsection{Distribuição espacial}

A ocorrência da predação por onças foi diferente em cada retiro e pasto da Fazenda Ouro Branco (Tabela 3). A maioria dos eventos de predação ocorreu na Colina Verde e Madereira, em todos os anos. No Zequinha, a predação foi baixa e ocorreu em 1999, 2000 e 2001. No Xodó, a predação foi igualmente baixa e apenas ocorreu em 2002 e 2003. Na Sede não ocorreu predação de bovinos em nenhum dos anos. No retiro Liberdade, ocorreu perda de dados sobre a predação de 1998 a 2001, pois o retireiro descartava as fichas de mortalidade após repassar os dados a seu superior. A predação na Liberdade $(n=53)$ permaneceu regular quando comparada com outros retiros no período de seis anos (Tabela 3). No entanto, quando comparada apenas nos anos de 2002 e 2003, foi semelhante à Colina Verde $(n=54)$ e maior que a Madeireira $(n=39)$.

Tabela 3. Freqüência anual da predação por onças nos diferentes retiros da Fazenda Ouro Branco, de 1998 a 2003

\begin{tabular}{lrrrrrrrr}
\hline Retiro & 1998 & 1999 & 2000 & 2001 & 2002 & 2003 & Total & $\%$ \\
Colina Verde & 7 & 13 & 23 & 35 & 24 & 30 & 132 & 42,7 \\
Madeireira & 21 & 17 & 12 & 15 & 30 & 9 & 104 & 33,7 \\
Liberdade & $-*$ & $-*$ & $-*$ & $-*$ & 34 & 19 & 53 & 17,2 \\
Zequinha & 0 & 2 & 7 & 1 & 0 & 0 & 10 & 3,2 \\
Xodó & 0 & 0 & 0 & 0 & 1 & 9 & 10 & 3,2 \\
Sede & 0 & 0 & 0 & 0 & 0 & 0 & 0 & 0 \\
Total & 28 & 32 & 42 & 51 & 89 & 67 & 309 & 100,0 \\
\hline
\end{tabular}

*(-): Dados perdidos de 1998 a 2001 no retiro da Liberdade (LB).

Do total de pastos $(n=218)$ existentes na Fazenda Ouro Branco, em apenas 68 $(31,2 \%)$ houve a incidência de predação por onças (Tabela 4). Apesar da predação ter sido mais freqüente na Colina Verde, sua ocorrência neste retiro ficou restrita a quase metade dos pastos, assim como na Liberdade. Na Madeireira, a predação foi alta e ocorreu em todos os pastos. No Zequinha e Xodó a predação foi baixa e restrita a poucos 
pastos. A Tabela 4 demonstra a quantidade de pastos com predação por onças em comparação com o número total de pastos nos diferentes retiros da Fazenda Ouro Branco.

Tabela 4. Pastos (n) com predação por onças nos diferentes retiros da Fazenda Ouro Branco, de 1998 a 2003

\begin{tabular}{lrrr}
\hline Retiro & Número de pastos (n) & Pastos com predação (n) & $\%$ \\
Colina Verde & 39 & 20 & 51,2 \\
Madeireira & 21 & 21 & 100,0 \\
Liberdade & 26 & 14 & 53,8 \\
Zequinha & 54 & 8 & 14,8 \\
Xodó & 39 & 5 & 12,8 \\
Sede & 39 & 0 & 0,0 \\
Total & 218 & 68 & - \\
\hline
\end{tabular}

A predação não ocorreu aleatoriamente. Houve uma seleção de áreas mais suscetíveis à predação entre os retiros e entre os pastos de cada retiro na Fazenda Ouro Branco. Todas as predações ocorreram próximas aos pastos localizados no entorno dos fragmentos florestais e das matas ciliares existentes na Fazenda e nas propriedades vizinhas. A maioria das predações ocorreu nos limites da Fazenda com outras propriedades e foi praticamente ausente na área central. A Figura 7 demonstra a ocorrência das predações de bovinos por onças nos pastos situados no entorno dos fragmentos florestais e das matas ciliares da Fazenda Ouro Branco. 


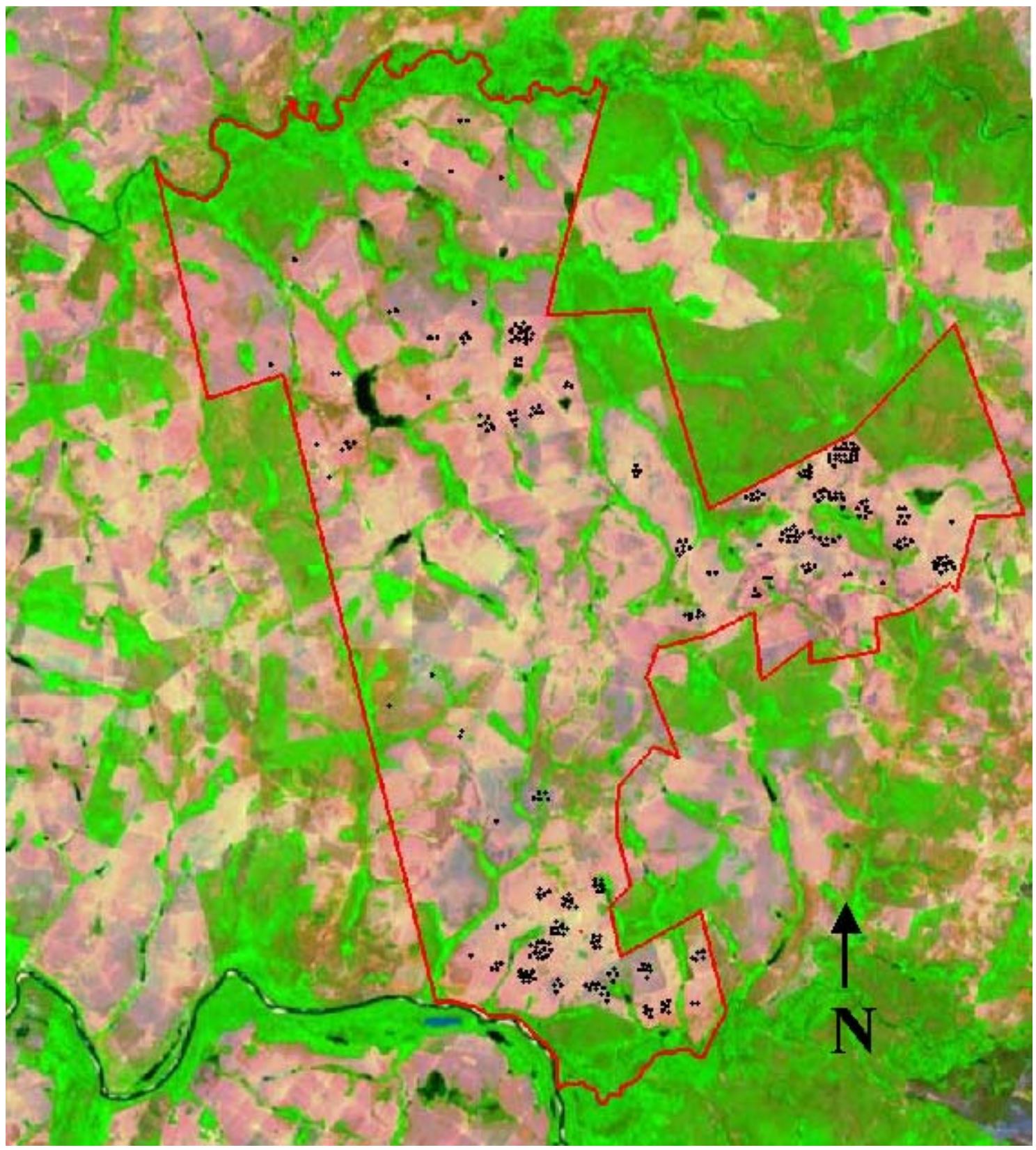

Figura 7 - Distribuição espacial da predação dos limites da Fazenda Ouro Branco, de 1998 a 2003 (Adaptado de Antonio Zumstein) 


\subsection{Biomassa}

A Sede teve a maior biomassa estimada $\left(\mathrm{kg} / \mathrm{km}^{2}\right)$ para o estoque total, seguida, nessa ordem, por Madeireira, Colina Verde, Liberdade, Zequinha e Xodó (Tabela 5). A estimativa da biomassa predada $\left(\mathrm{kg} / \mathrm{km}^{2}\right)$ foi mais representativa na Madeireira, seguida, nessa ordem, por Colina Verde, Liberdade, Xodó. No entanto, quando analisado apenas os anos de 2002 e 2003, a estimativa da biomassa predada foi maior na Liberdade $\left(555,72 \mathrm{~kg} / \mathrm{km}^{2}\right)$, seguida, nessa ordem, por Madeireira $\left(430,05 \mathrm{~kg} / \mathrm{km}^{2}\right)$, Colina Verde $\left(384,45 \mathrm{~kg} / \mathrm{km}^{2}\right)$, Xodó $\left(72,31 \mathrm{~kg} / \mathrm{km}^{2}\right)$ e foi ausente no Zequinha.

Tabela 5. Estimativa da biomassa do estoque de bovinos e da biomassa predada em por retiro na Fazenda Ouro Branco, de 1998 a 2003

\begin{tabular}{lrrrr}
\hline Retiro & \multicolumn{1}{c}{$\begin{array}{c}\text { Biomassa do } \\
\text { estoque }(\mathrm{kg}) *\end{array}$} & $\begin{array}{r}\text { Biomassa do } \\
\text { estoque }\left(\mathrm{kg} / \mathrm{km}^{2}\right)\end{array}$ & $\begin{array}{r}\text { Biomassa } \\
\text { predada }(\mathrm{kg})\end{array}$ & $\begin{array}{r}\text { Bredada }\left(\mathrm{kg} / \mathrm{km}^{2}\right) \\
\text { Colina Verde }\end{array}$ \\
Madeireira & 390,000 & $19.934,90$ & 23,100 & 939,88 \\
Liberdade & 288,750 & $17.300,77$ & 18,200 & $1.146,81$ \\
Zequinha & 434,000 & $12.594,31$ & 9,275 & 555,72 \\
Xodó & 207,900 & $8.590,90$ & 1,750 & 50,78 \\
Sede & 539,000 & $21.137,25$ & 1,750 & 72,31 \\
& & $20.951,48$ & 0,000 & 0,00
\end{tabular}

* Biomassa de bovinos (kg): Dados referentes ao estoque total de março de 2003.

O estoque médio anual $(12.538 \pm 2.679)$ representou uma biomassa média anual de $15.528,3 \mathrm{~kg} / \mathrm{km}^{2}$ de bovinos distribuídos nas áreas de pastagens da Fazenda. A média de bovinos comercializada $(1.221 \pm 875)$ representou uma biomassa média anual de $1.512,2 \mathrm{~kg} / \mathrm{km}^{2}$ (aproximadamente $10 \%$ do estoque médio anual). A predação média anual representou uma biomassa estimada em $63,8 \mathrm{~kg} / \mathrm{km}^{2}$, equivalente a $0,4 \%$ da biomassa média anual $\left(\mathrm{kg} / \mathrm{km}^{2}\right)$ do estoque e $4,2 \%$ da biomassa comercializada.

A classe de biomassa mais vulnerável variou de 50 a $180 \mathrm{~kg}$, que correspondeu às classes de idade de 0 a 9 meses (Tabela 6). A classe de idade mais representativa em 
termos de biomassa total predada foi de 3 a 6 meses $(n=10.680 \mathrm{~kg}, 36,2 \%)$, seguida de 0 a 3 meses $(n=8.500 \mathrm{~kg}, 28,8 \%)$ e de 6 a 9 meses $(n=7.380 \mathrm{~kg}, 25 \%)$ (Tabela 6).

Tabela 6. Biomassa média (kg), de acordo com a classe de idade (meses) dos bovinos predados na Fazenda Ouro Branco, de 1998 a 2003

\begin{tabular}{lrrr}
\hline Classe de idade (meses) & Predação (n) & Peso médio (kg) & Biomassa (kg) \\
$0-3$ & 170 & 50 & 8.500 \\
$3-6$ & 89 & 120 & 10.680 \\
$6-9$ & 41 & 180 & 7.380 \\
$9-12$ & 6 & 275 & 1.650 \\
$12-24$ & 0 & 350 & 0.000 \\
$>24$ (Vacas) & 3 & 420 & 1.260 \\
Total & 309 & - & 29.470 \\
\hline
\end{tabular}

\subsection{Prejuízo econômico}

$\mathrm{O}$ estoque médio anual teve um valor estimado em $\mathrm{R} \$ 4.388 .300,00$ (US\$ 1.406.506,40). As vendas representaram o valor médio anual de R\$ 507.728,00 (US\$ 162.733,33). O prejuízo econômico resultante da predação por onças foi de $\mathrm{R} \$$ $80.700,00$ (US\$ 25.865,38) durante seis anos, com médias de R\$ 13.450,00 (US\$ $4.310,89$ ) por ano, R\$ 1.120,83 (US\$ 359,24) por mês e R \$ 37,36 (US\$ 11,97) por dia. A predação média anual representou um prejuízo econômico equivalente a $0,3 \%$ do valor estimado para o estoque e a 2,6\% do valor médio anual das vendas. Foi muito menor do que o prejuízo causado por outras causas acumuladas, que resultou no total de $\mathrm{R} \$ 368.385,00$ (US\$ 118.072,11), com médias de R\$ 61.397,75 (US\$ 19.678,76) por ano, R\$ 5.116,45 (US\$ 1.639,88) por mês e R\$ 170,54 (US\$ 54,66) por dia. O valor econômico resultante da predação foi diferente de acordo com a categoria dos bovinos (Tabela 7). 
Tabela 7. Prejuízo econômico (R\$ e US\$) de acordo com categoria de bovinos predados por onças na Fazenda Ouro Branco, de 1998 a 2003

\begin{tabular}{lrrrrr}
\hline Categoria de bovinos & Predação (n) & Unitário *R\$(US\$) & Total (R\$) & Total (US\$) \\
Bezerra/Bezerro & 306 & 260,00 & $(83,33)$ & $79.560,00$ & $25.500,00$ \\
Novilha/Garrote & 0 & $370,00(118,58)$ & 0,00 & 0,00 \\
Vaca & 3 & $380,00(121,79)$ & $1.140,00$ & 365,38 \\
Boi & 0 & $500,00(160,25)$ & 0,00 & 0,00 \\
Touro & 0 & $900,00(288,46)$ & 0,00 & 0,00 \\
Total & 309 & - & - & $80.700,00$ & $25.865,38$
\end{tabular}

*Dados calculados em R\$ em dezembro de 2002 e convertidos para US\$ em julho de 2004.

\subsection{Identificação do predador}

Parte das carcaças $(n=69,22,3 \%)$ resultantes das predações causadas por onçaparda (Figura 9) e onça-pintada (Figura 10) foi identificada e vistoriada de outubro de 2002 a maio de 2003. A predação por onças-pardas e onças-pintadas difere entre si (Tabela 8). A maioria das predações foi causada por onças-pardas e poucas predações foram causadas por onças-pintadas (Tabela 8).

Tabela 8. Predações de bovinos (n) por onças-pardas (Puma concolor) e onças-pintadas (Panthera onca) nos retiros da Fazenda Ouro Branco, de outubro de 2002 a maio de 2003

\begin{tabular}{lrrr}
\hline Retiro & Onça-parda & Onça-pintada & Total \\
Colina Verde & 26 & 3 & 29 \\
Madeireira & 25 & 1 & 26 \\
Liberdade & 12 & 1 & 13 \\
Xodó & 1 & 0 & 1 \\
Total & 64 & 5 & 69 \\
\hline
\end{tabular}




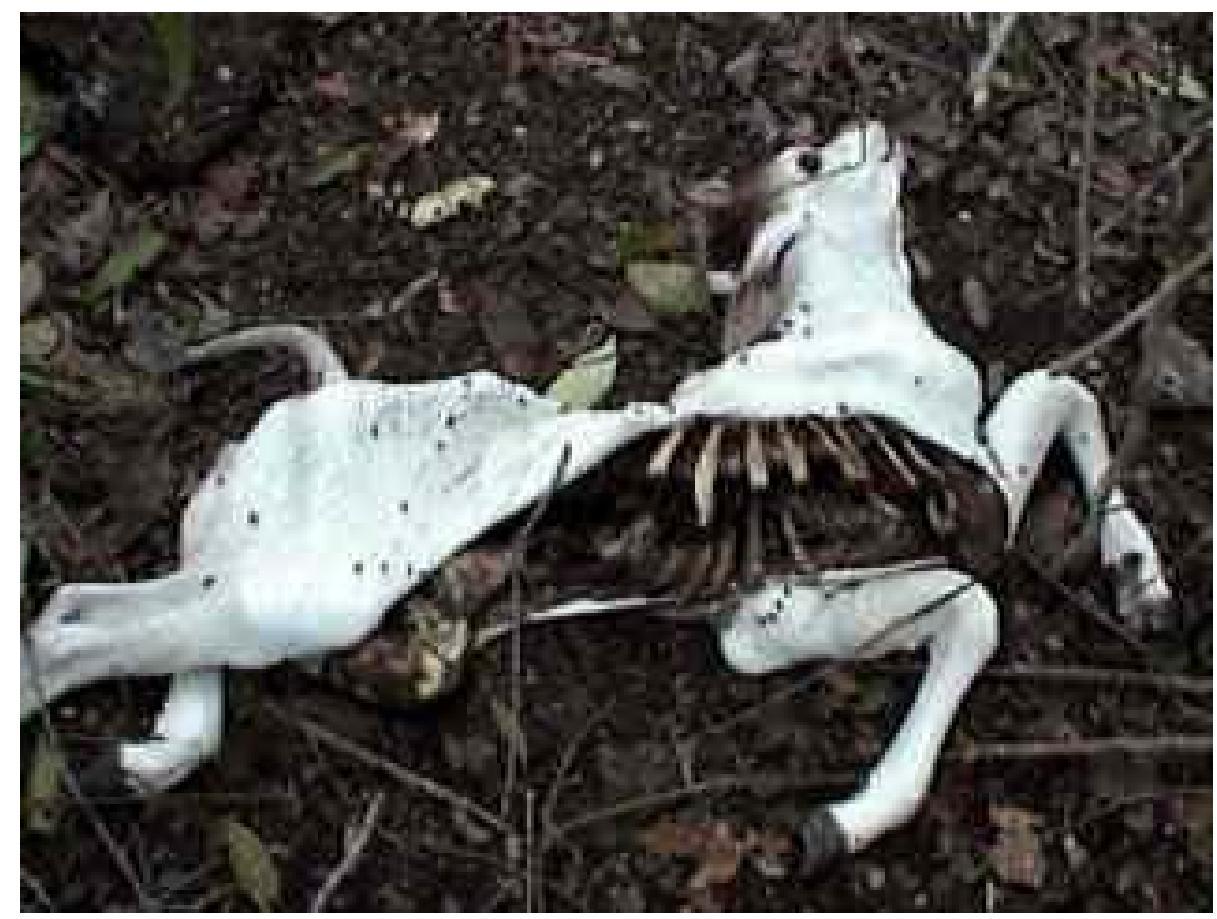

Figura 9 - Predação de bezerro por onça-parda (Puma concolor) na Fazenda Ouro Branco, em novembro de 2002

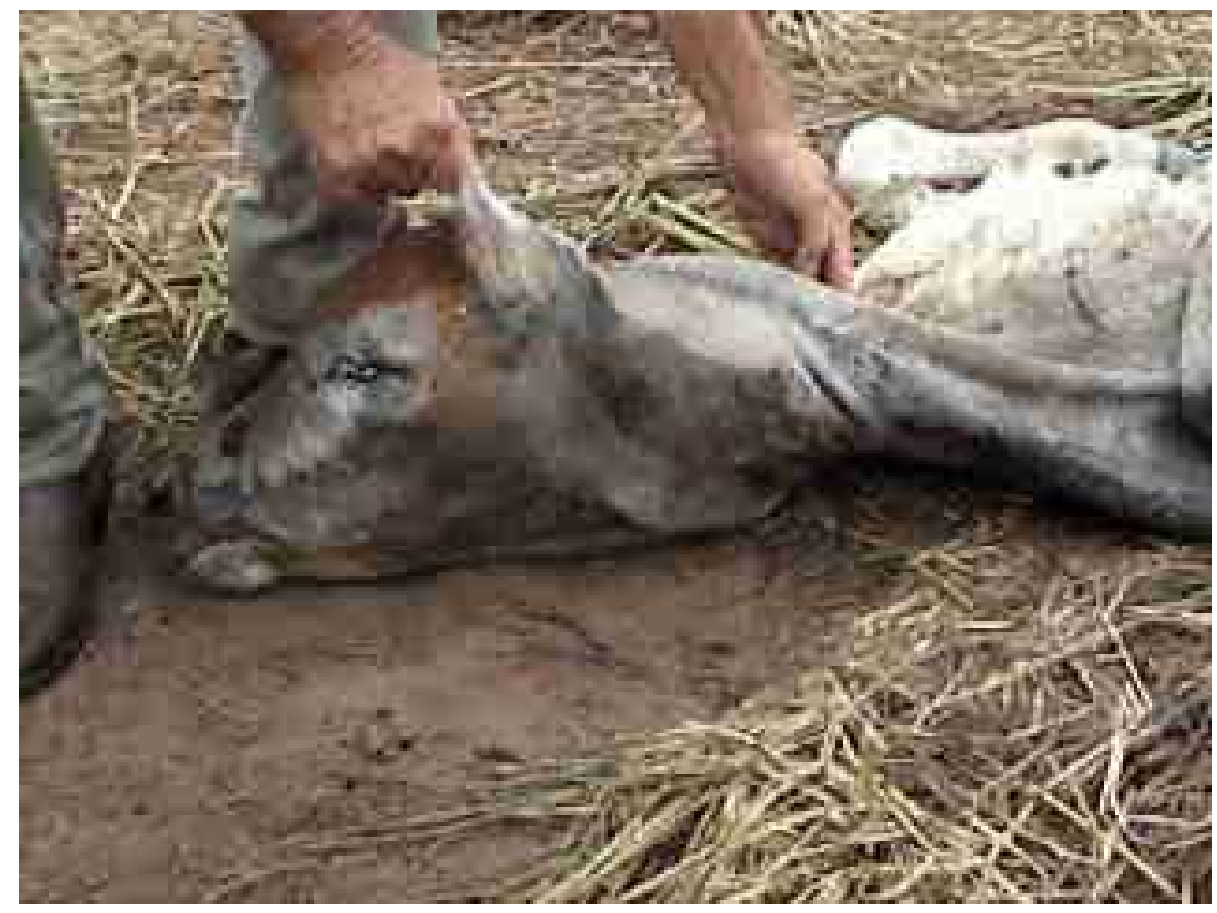

Figura 10 - Predação de bezerro por onça-pintada (Panthera onca) na Fazenda Ouro Branco, em fevereiro de 2003 
A Tabela 9 demonstra a diferença da predação por onças-pardas e onças-pintadas de acordo com a classe de idade (meses) dos bovinos. A onça-parda predou bezerros menores e as onças-pintadas predou bezerros maiores (Tabela 9).

Tabela 9. Predação por onças-pardas (Puma concolor) e onças-pintadas (Panthera onca), de acordo com a classe de idade (meses) dos bovinos na Fazenda Ouro Branco, de outubro de 2002 a maio de 2003

\begin{tabular}{lrrr}
\hline Classe de idade (meses) & Onça-parda & Onça-pintada & Total \\
$0-3$ & 42 & 0 & 42 \\
$3-6$ & 22 & 3 & 25 \\
$6-9$ & 0 & 2 & 2 \\
$9-12$ & 0 & 0 & 0 \\
$>24$ & 0 & 0 & 0 \\
Total & 64 & 5 & 69 \\
\hline
\end{tabular}

\subsection{Caça}

Apesar de o proprietário não permitir a caça, foram encontrados por diversas vezes indícios de caça na Fazenda. Durante um dos trajetos, foram encontrados dois caçadores armados com espingarda 22 dentro na reserva legal do Crixás, na Madeireira. Durante outros trajetos, foram encontrados constantes sinais da presença humana, como ranchos de palha, arapuca, jirau, rastros e latidos de cães.

As atividades de caça foram bastante freqüentes em uma das famílias na vizinhança da Fazenda Ouro Branco. Foi constatada a caça de espécies-presas como anta (Tapirus terrestris), veado (Mazama sp.), cateto e tatu para alimentar os cães. Também ocorreu a caça-controle de onças pintada e onças-pardas (Figura 11). A família relatou que alguns fazendeiros ofereciam aos caçadores a recompensa de três bovinos por onça abatida.

O maior caçador de onças da região morava na cidade de São Miguel do Araguaia e era conhecido por toda a população local. Quando as pessoas tomavam 
conhecimento desta pesquisa, logo se referiam ao caçador como importante fonte de informações sobre as onças. O contato com esse caçador foi realizado por meio do administrador da Fazenda Ouro Branco, que era seu conhecido. Durante uma visita, ele percorreu as áreas onde já havia caçado dentro da Fazenda. As caçadas de onças sempre ocorreram nas reservas dos rios Crixás e Gregório, no retiro da Madeireira. O caçador relatou que foi contratado por inúmeras vezes pelos antigos administradores para matar onças predadoras de bovinos e que isso era uma prática muito comum (Figura 12). Matou diversas onças dentro da Fazenda e nas áreas vizinhas, utilizando os métodos de caçada com cachorros e de espera com esturrador (equipamento feito pelo caçador para atrair exclusivamente onças-pintadas por meio da reprodução de sua vocalização). $\mathrm{O}$ caçador havia aprendido as técnicas com seu pai, que também caçava onças, e deixou bem claro a sua preferência por onças-pintadas, pois só havia caçado duas onças-pardas, enquanto caçou cerca de 40 onças-pintadas na região.

Por meio dos relatos de caça, crânios, couros e fotos de onças caçadas foram registradas 8 mortes de onças na Fazenda Ouro Branco e nas propriedades vizinhas Fazenda Pintado, Fazendo Rio Vermelho e Fazenda Lagoa da Prata, no período de seis anos (Tabela 10).

Tabela 10. Onças-pardas (Puma concolor) e onças-pintadas (Panthera onca) mortas na Fazenda Ouro Branco e nas propriedades vizinhas (Fazenda Pintado, Fazendo Rio Vermelho e Fazenda Lagoa da Prata), de 1998 a 2003

\begin{tabular}{lrrr}
\hline Espécie & Macho & Fêmea & Total \\
Onça-parda (Puma concolor) & 3 & 0 & 3 \\
Onça-pintada (Panthera onca) & 2 & 3 & 5 \\
Total & 5 & 3 & 8 \\
\hline
\end{tabular}




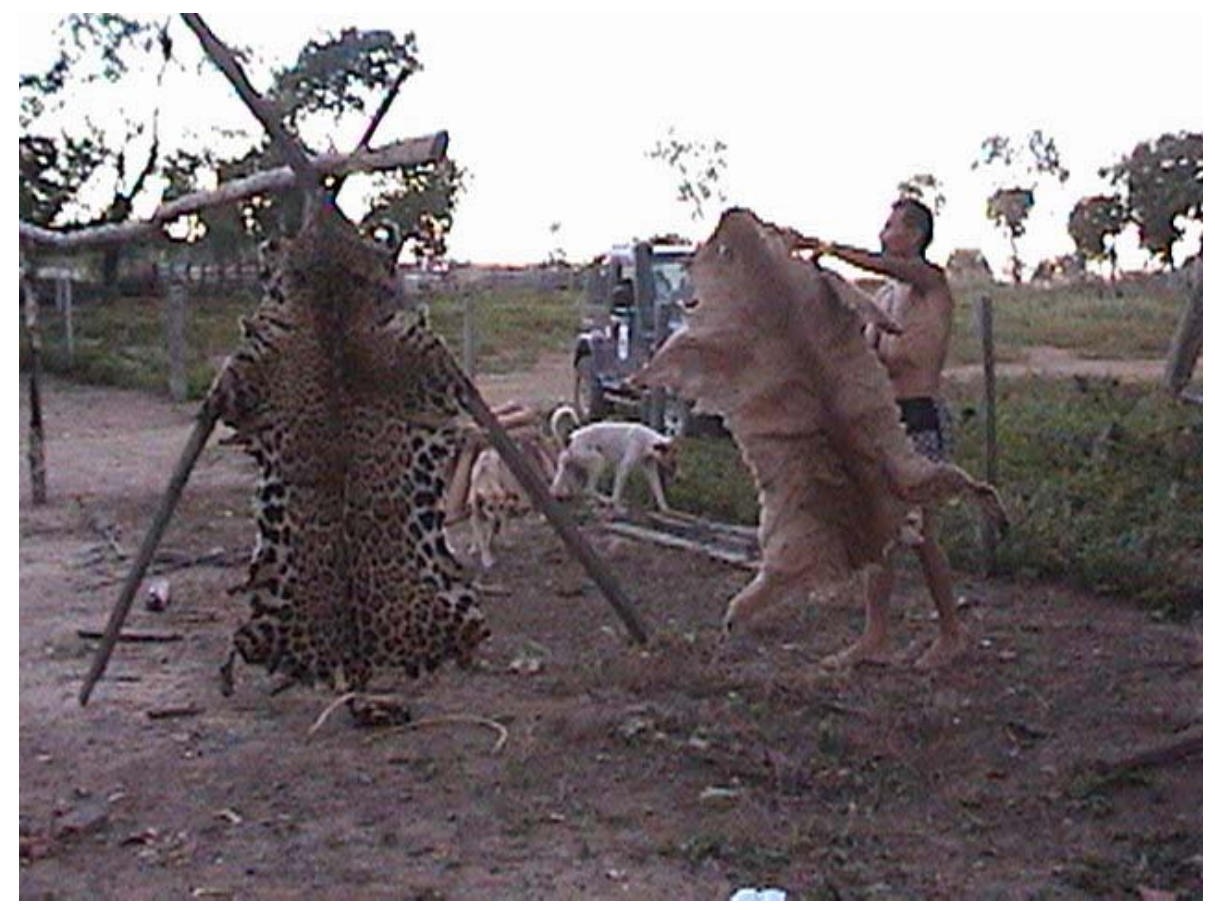

Figura 11 - Peles de onça-pintada (Panthera onca) e de onça-parda (Puma concolor), ambos machos, caçadas em 2001, na Fazenda Ouro Branco

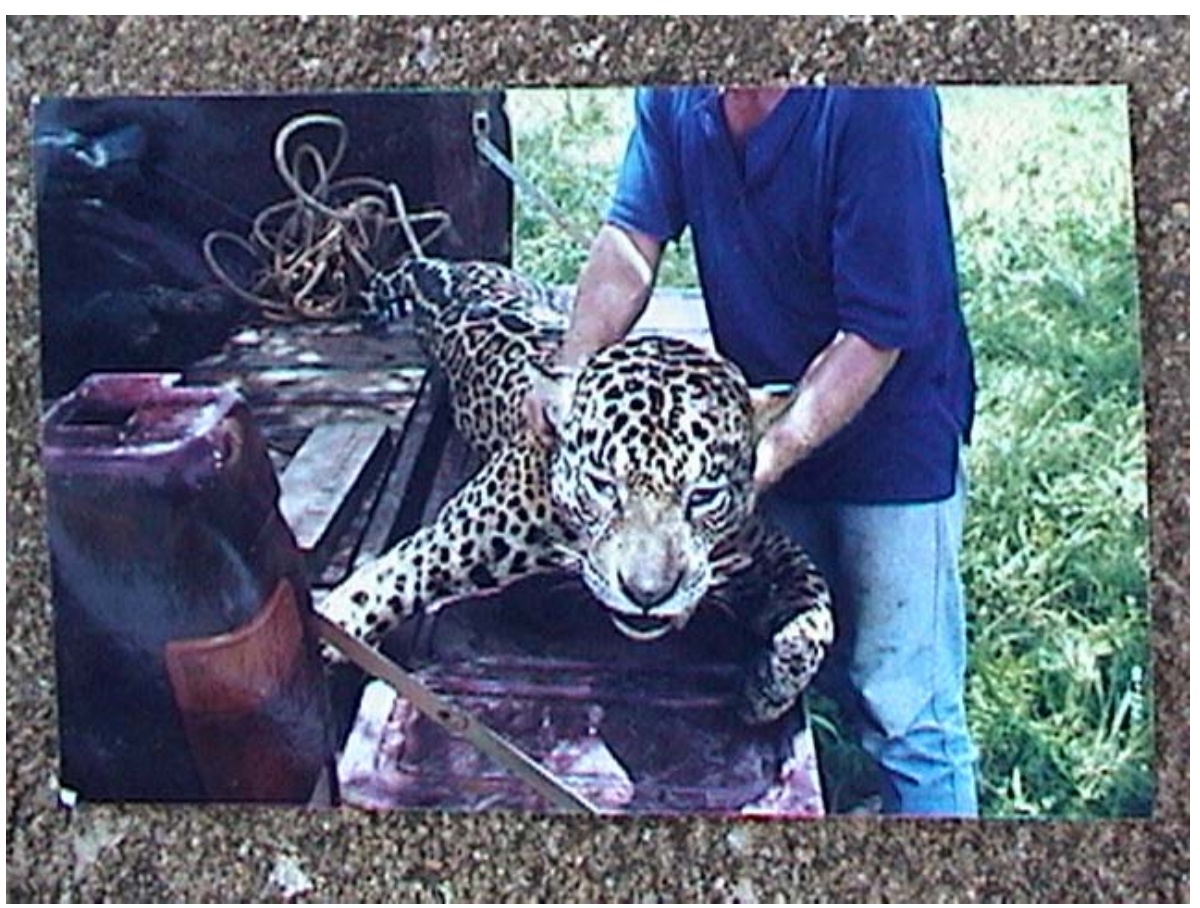

Figura 12 - Onça-pintada (Panthera onca) macho, caçada em fevereiro de 1998 na Fazenda Ouro Branco 


\section{DISCUSSÃO}

A predação por onças representou $21,7 \%$ da mortalidade total de bovinos na Fazenda Ouro Branco durante seis anos e foi maior que à registrada nos Ilanos Venezuelanos, onde a predação por onças-pardas e onças-pintadas representou 13\% da mortalidade de bovinos no período de dez anos (Polisar et al., 2003). A predação na Fazenda Ouro Branco foi menor que a mortalidade por outras causas $(78,3 \%)$ acumuladas. Possivelmente, a predação seria mais representativa como causa simples, isto é, se a mortalidade por outras causas acumuladas fosse apresentada separadamente como causas específicas (p.ex.: doenças, acidentes, entre outros). Algumas pesquisas indicaram que doenças, desnutrição e acidentes nos rebanhos domésticos causam maiores perdas do que o ataque por predadores silvestres (Schaller, 1983; Quigley \& Crawshaw, 1992; Hoogesteijn et al., 1993; Oli et al., 1994; Mazzolli et al., 2002). Em Acurizal, no Pantanal de Mato Grosso, durante a estação de nascimentos (julho e outubro), de dez bezerros mortos apenas um foi predado por onça-pintada e os outros morreram por outras causas, como desnutrição e doenças (Schaller, 1983).

A predação média anual $(51,5 \pm 18,4)$ representou $0,4 \%$ do estoque médio anual de bovinos na Fazenda Ouro Branco e foi semelhante ao de propriedades rurais no entorno do Parque Nacional de Iguaçú, Estado do Paraná (Conforti \& Azevedo, 2003). Nas propriedades do entorno do Parque Nacional de Tsavo, no Kenya, a maioria das predações foi causada por leões e representou em média 2,4\% do estoque anual (Patterson et al., 2004). Em algumas regiões das províncias de Qinghai e Gansu, na China, a predação causada por leopardos das neves e por lobos representou $0,5 \%$ do estoque anual dos animais domésticos de cinco proprietários (Schaller et al., 1988). No

entorno da Área de Conservação de Annapurna, no Nepal, a predação causada pelo 
leopardo das neves foi maior e representou uma média de 2,6\% do estoque total, no período de dois anos (Oli et al., 1994). Em larga escala, a predação por felinos é geralmente baixa, na ordem de até 3\% do estoque por ano (Jackson \& Nowell, 1996).

$\mathrm{Na}$ Fazenda Ouro Branco, a predação diferenciou-se entre as categorias dos bovinos, sendo que a faixa etária mais predada foi de bezerro $(n=306,99 \%)$. A predação associou-se fortemente à idade (meses) dos animais predados $\left(\mathrm{p}<0.05 ; \mathrm{r}_{\mathrm{s}}=-0,80\right)$. Conforme o aumento da idade dos bovinos ( $>12$ meses), a predação se reduziu claramente. Outras pesquisas também indicaram que os bezerros foram os mais predados por onças (Hoogesteijn et al., 1993; Schaller, 1983). Em propriedades rurais do entorno do Parque Nacional de Iguaçú, foi registrada a predação de 36 bovinos por onçaspintadas, sendo que a maioria foi de bezerros de até um ano e meio de idade e algumas vacas adultas (Crawshaw, 1995). De quatro animais predados por onça-pintada no Pantanal, três foram bezerros (6-8 meses) e apenas um boi com cerca de dois anos (Childs, 1998).

$\mathrm{Na}$ Fazenda Ouro Branco, a predação média anual de bezerros $(51 \pm 23)$ representou $1,2 \%$ da média anual de nascimentos. A razão sexual dos animais predados foi diferente da dos nascidos. Possivelmente, os bezerros machos foram mais predados por se afastarem, naturalmente, da mãe primeiro que as fêmeas.

A predação foi sazonal e influenciada pelo período dos nascimentos de bezerros na Fazenda Ouro Branco. O período dos nascimentos também foi sazonal e se associou à precipitação $(\mathrm{mm})$ mensal $\left(\mathrm{p}<0,01 ; \mathrm{rs}_{\mathrm{s}}=0,43\right)$. A maioria dos nascimentos $(76,2 \%)$ e das predações $(71,8 \%)$ ocorreu na estação chuvosa. A Fazenda Ouro Branco, manipulou o período dos nascimentos por meio da estação de monta e da inseminação artificial, para possibilitar que os animais se desenvolvam no início das chuvas, período de maior abundância de pastagens na região. Tal fato favoreceu a incidência da predação sobre bezerros no período dos nascimentos. Polisar et al. (2003) também constataram que a predação foi maior nos meses de nascimentos de bezerros (de agosto a outubro), com uma média de 20 bezerros predados por ano.

Na Fazenda Ouro Branco, a predação foi mais freqüente na estação chuvosa, o que pode ser explicado pela ocorrência dos nascimentos de bezerros no mesmo período. 
Em outras pesquisas, a sazonalidade climática na ocorrência de predação, foi constatada para a onça-parda, sendo mais freqüente no inverno (Mazzolli et al., 2002), para os leopardos das neves, sendo também mais freqüente durante o inverno (Oli et al., 1994) e para os leões, sendo mais freqüente na estação chuvosa (Patterson et al., 2004).

A predação não foi aleatória e foi restrita a alguns retiros e pastos na Fazenda Ouro Branco. O fato de os retiros e pastos terem diferentes áreas (ha), biomassa de bovinos, manejo, hidrografia, vegetação, refúgios da fauna silvestre, entre outros, vem dificultar uma análise mais profunda, que indicaria quais dessas variáveis mais influenciaram a predação. A incidência de predação nos mesmos pastos durante seis anos sugere que existem áreas com maior probabilidade de ataques. Diversas onças predadoras de bovinos foram eliminadas em locais que depois foram igualmente ocupados por outros indivíduos, que também predaram os bovinos. Tal fato sugere que a predação foi influenciada pelo comportamento biológico das onças residentes na Fazenda Ouro Branco. Em Belize, foi observado que as onças-pintadas ocuparam rapidamente a área de indivíduos que foram mortos. Nesse caso, as áreas podem ser ocupadas por onças "não-problemas", que não atacam os bovinos ou onças predadoras de rebanhos domésticos (Rabinowitz, 1986).

Apesar de não haver ocorrido ataques em todos os pastos próximos às reservas florestais e às matas ciliares, ficou evidente que todas as predações ficaram restritas aos pastos mais próximos das reservas florestais e das matas ciliares da Fazenda. O fato de não ter ocorrido predação no retiro da Sede pode ser explicado pela ausência de extensos fragmentos florestais, por presença de estradas bastante utilizadas e de diversas residências. No entorno de Unidades de Conservação, no Estado do Paraná, os locais com ocorrência de predação por onças sempre estavam próximos a até $500 \mathrm{~m}$ da borda da floresta (Leite, 2000). Fato semelhante foi registrado com as capivaras (Hydrochaeris hydrochaeris), que causavam danos em plantações de milho adjacentes a fragmentos florestais. Nesse caso, à medida que a plantação se distanciava da mata, o dano era reduzido, relacionando-se esse fato, com as proximidades dos recursos florestais e aquáticos, fundamentais para a espécie (Ferraz et al., 2003). 
A predação ocorreu independente da disponibilidade de biomassa de bovinos $\left(\mathrm{kg} / \mathrm{km}^{2}\right)$ existente em cada retiro. O retiro da Sede teve a maior biomassa de bovinos e nenhuma predação por onças, certamente, esse retiro possui outros fatores, que são mais importantes para a ausência da predação do que a disponibilidade de bovinos. A biomassa média anual de bovinos foi de $15.528 \mathrm{~kg} / \mathrm{km}^{2}$ em toda a Fazenda Ouro Branco, muito maior do que a biomassa de $7.363 \mathrm{~kg} / \mathrm{km}^{2}$ nos Ilanos Venezuelanos (Polisar et al., 2003), de $4.900 \mathrm{~kg} / \mathrm{km}^{2}$ na Fazenda Estância Miranda, no Pantanal (Crawshaw \& Quigley, 1984) e de $3.750 \mathrm{~kg} / \mathrm{km}^{2}$ em Acurizal, no Pantanal (Schaller, 1983). Na Fazenda Ouro Branco, a categoria mais representativa em termos de biomassa predada também foi o bezerro. Considerando-se a massa $(\mathrm{kg})$ das diferentes categorias, a biomassa mais consumida pelas onças foi de $120 \mathrm{~kg}$, que correspondeu à classe de idade de 3 a 6 meses. O mesmo ocorreu nos Ilanos Venezuelanos, onde a classe mais vulnerável à predação por onças foi de 3 a 6 meses de idade (Polisar et al., 2003).

O prejuízo econômico resultante da predação, representou $0,3 \%$ do valor estimado para o estoque médio de bovinos e $2,6 \%$ do valor médio anual das vendas. $\mathrm{O}$ prejuízo econômico causado pela predação durante seis anos foi proporcionalmente menor na Fazenda Ouro Branco (US\$ 25.865,38) do que em outras áreas estudadas. No entorno do Parque Nacional de Foz do Iguaçú, os registros de predações por onças envolveram prejuízos estimados em US\$ 5.400,00, em três a quatro meses de observação (Crawshaw, 1995). Em propriedades rurais do entorno do Parque Nacional de Tsavo, os leões predadores foram responsáveis pelo prejuízo econômico de US\$ 8.749,00 por ano (Patterson et al., 2004). Em outros casos, a predação de bovinos por onças foi proporcionalmente maior na Fazenda Ouro Branco. Em duas diferentes pesquisas no entorno do Parque Nacional de Foz do Iguaçú, os registros de predações por onças foram estimados em US\$ 17.000,00 durante quatro anos (Manzatti, 1999) e US\$ 3.000,00 por ano (Conforti \& Azevedo, 2003). No Estado de Santa Catarina, o prejuízo causado pelas onças-pardas representou US\$1.890,00, menos que as mortes por outras causas que foi US\$23.520,00 (Mazzolli et al., 2002).

A predação por onças-pardas e onças-pintadas foi diferente entre os retiros e pastos da Fazenda Ouro Branco. A maioria das predações de bovinos foi causada por 
onças-pardas. Também, existiu uma diferença na classe de idade dos animais predados pelas onças-pardas e pelas onças-pintadas. A onça-parda predou bezerros menores ( $0-6$ meses) e a onça-pintada predou bezerros maiores (3-9 meses). Diversas pesquisas indicaram diferenças de comportamento alimentar entre a onça-parda e a onça-pintada. Existe uma diferença de massa $(\mathrm{kg})$ entre as presas escolhidas por cada espécie (Leite, 2000). A onça-pintada tende a se utilizar de presas de grande e médio porte e a onçaparda de presas de médio e pequeno porte, especialmente quando essas espécies são simpátricas (Scognamillo et al., 2003). No Pantanal, a predação pela onça-parda e pela onça-pintada variou em relação às classes de tamanho e de idade dos bovinos. A predação por onças-pardas foi mais freqüente em bezerros $(92 \%)$ e vacas $(8 \%)$ e a predação por onças-pintadas foi mais freqüente em vacas (57\%), bezerros $(32 \%)$, bois (7\%) e touros (4\%) (Crawshaw \& Quigley, 1984).

Independentemente do prejuízo econômico ter sido alto ou baixo, a predação resultou muitas vezes no extermínio das onças. Em algumas partes do mundo, é permitido que os predadores sejam legalmente exterminados ou removidos pelo proprietário, que deve convidar um oficial do governo para verificar o grau de predação e autorizar o abate (Jackson \& Nowell, 1996). No Brasil, de acordo com o artigo 37 da Lei de Crimes Ambientais, "não é crime o abate de animal, quando realizado, entre outros casos, para proteger lavouras, pomares e rebanhos da ação predatória ou destruidora de animais, desde que legal e expressamente autorizado pela autoridade competente" (Ministério do Meio Ambiente, 2000). Para administrar o conflito causado pela predação, atender às denúncias em propriedades, desenvolver atividades de pesquisa e manejo, entre outros aspectos, foi criado o Centro Nacional de Pesquisas para a Conservação dos Predadores Naturais do Instituto Brasileiro do Meio Ambiente e dos Recursos Naturais Renováveis (CENAP/IBAMA), que atua desde 1994 (Portaria ${ }^{\circ}$ 78/94 e n $\mathrm{n}^{\circ}$ 101/95). Desde então, autoridades governamentais nacionais e estaduais têm recebido grande número de chamados, envolvendo a predação de animais domésticos. Contudo, a falta de profissionais treinados e as falhas nos sistemas de registro das ocorrências têm impedido que ações eficazes sejam tomadas (Pitman et al., 2002; Verdade \& Campos, 2004). 
É necessário, capacitar técnicos para avaliar os danos causados pela fauna silvestre, incluindo o problema da predação. É fundamental oferecer treinamento especializado, desde a graduação, a biólogos, engenheiros agrônomos e áreas afins; em especial, aos especialistas nas áreas de bovinocultura e suinocultura. Esses especialistas poderiam elaborar projetos de produção animal considerando a presença de grandes felinos na área, com a finalidade de reduzir a predação por meio de um conjunto de estratégias de manejo. Tais profissionais poderiam desenvolver mapas da distribuição espacial da predação como forma de subsidiar o desenvolvimento de medidas preventivas para reduzir a predação em propriedades rurais. Também poderiam elaborar previsões de gastos anuais discriminando os custos econômicos a serem reservados para as prováveis perdas resultantes da predação. No Brasil, alguns manuais têm sido elaborados com os objetivos de orientar os profissionais no trabalho de campo e de sugerir medidas preventivas para reduzir a predação (Pitman et al., 2002). Também se torna necessário elaborar manuais para os produtores rurais e para a população local, que tenham como enfoque a educação ambiental (Leite \& Crawshaw, 1999).

Um grande incentivo para reduzir o prejuízo causado pela predação seria o abatimento parcial do Imposto Territorial Rural (ITR) para fazendeiros que têm grandes propriedades e que comprovem perdas relativas à predação por onças. Para Hoogesteijn \& Chapman (1997), a incorporação de fazendas de bovinos em um programa de conservação requer que as agências do governo e da conservação ajudem latifundiários a desenvolver um sistema que assegure a aplicação de regulamentos para a conservação em suas propriedades. Para continuidade a longo prazo, uma rede formalizada de fazenda/reserva teria melhor possibilidade para a sustentabilidade. Tal rede poderia envolver proprietários que apreciam incentivos tributários, proteção da especulação de terra, "status" social prestigioso oficialmente reconhecido e tenham em suas propriedades potencial para contribuição significativa aos esforços de conservação.

Existe entre os especialistas, uma grande controvérsia respeito das estratégias de redução da predação por onças. Essas estratégias envolvem a translocação (Rabinowitz, 1986; Linnell et al., 1997), a indenização econômica (Verdade \& Campos, 2004), a proibição da caça e a sugestão de diversas medidas preventivas (Pitman et al., 2002). O 
mesmo ocorre nos Estados Unidos, onde o conflito entre os vários grupos de interesse tem aumentado. Acredita-se que seja necessário reduzir o conflito entre os grupos de interesse para definir uma política de manejo de interesse público para que onças possam coexistir com seres humanos (Laundré \& Clark, 2003).

Enquanto as medidas não forem testadas, não será possível afirmar qual conjunto de medidas é mais recomendado. Dessa forma, se evitariam custos adicionais com medidas que não funcionam ou que demoram muito tempo para funcionar. Em outros países, muitos experimentos foram realizados para se conhecer a melhor estratégia de minimizar a predação. Uma pesquisa nos Estados Unidos utilizou 11 anos de dados para demonstrar qual é a melhor proposta de manejo a ser implementada para os pumas serem caçados de forma controlada (Laundré \& Clark, 2003).

Um experimento apropriado à Fazenda Ouro Branco seria afastar os bezerros e observar se as onças se deslocariam até as áreas mais afastadas do fragmento ou até o centro da Fazenda para predá-los. Caso ela vá atrás dos bezerros, não adiantará deslocálos em certa medida. Poder-se-ia, também, verificar se, em áreas onde os bezerros foram retirados, a predação ocorrerá sobre animais mais velhos. Dessa forma, poderia-se ter segurança quanto a diminuição ou não da predação, caso fossem retirados os bezerros das áreas vulneráveis.

Outro experimento ideal seria tomar três ou mais fazendas, onde o período de nascimento dos bezerros é diferente, para verificar a sazonalidade da predação. Esse experimento poderia confirmar se a predação de bezerros se diluiria ou não caso os nascimentos ocorressem em igual período do ano em todas as fazendas de uma mesma região. Dessa forma, seria possível saber se ocorrerá ou não a sazonalidade na predação por onças de acordo com o período de nascimentos dos bezerros em diferentes propriedades rurais.

Também, tornam-se necessários o monitoramento das onças com a utilização da telemetria, de armadilhas fotográficas, de rastros, de fezes, de carcaças de presas para estimar a abundância da população de onças e saber quantas e quais atacam animais domésticos. Pode-se procurar saber qual é o período de reprodução e de nascimento das onças, verificando se coincide com o de nascimento dos bezerros. Dessa forma, a 
implementação de medidas preventivas se tornará mais eficiente. Outra possibilidade consiste em avaliar a abundância de presas silvestres, utilizando-se trajetos lineares para verificar se a abundância e a biomassa de presas é maior ou menor que a abundância e a biomassa de rebanhos domésticos. Afinal, de acordo com Terborgh (1990), a capacidade de um ecossistema manter grandes felinos está diretamente relacionada à abundância de suas presas. Em Botswana, um estudo utilizou a abundância de presas silvestres para investigar a ecologia alimentar e espacial dos leões. Esse estudo demonstrou que existe associação entre o aumento de presas e a redução na predação de rebanhos domésticos, comprovando, assim, que as presas silvestres podem "proteger" os rebanhos domésticos da predação (Hemson, 2003).

O problema da conservação não é apenas biológico, mas também econômico, social e político. Portanto, no caso da conservação das onças-pintadas e das onçaspardas, não basta estudar e conhecer a biologia e a ecologia das espécies, e sim entender a percepção humana em relação à presença desses animais, assim como as atitudes positivas e negativas resultantes dessa interação. A partir desta visão, torna-se necessária a elaboração de estratégias que evitem ou reduzam a predação e que tenham apoio e incentivo dos proprietários rurais.

As medidas preventivas podem ser elaboradas com a ajuda participativa da comunidade local, das instituições governamentais e não-governamentais e das instituições privadas. Sendo que um dos fatores mais importantes consiste em entender como a população humana de determinada região se comporta frente à presença de animais silvestres. Isso é fundamental ao implemento de estratégias de manejo participativo. É necessário elaborar estratégias de conservação que sejam apoiadas pelas populações locais, juntamente com instituições governamentais e não-governamentais e instituições privadas, nacionais e internacionais. 


\subsection{Recomendações}

É necessária uma abordagem científica envolvendo aspectos bioecológicos e sócioeconômicos (Figura 13). Sendo enorme a complexidade dessas interações, um grande esforço deve ser feito para minimizar os danos causados pelo conflito entre a produção econômica e a conservação das onças. A seguir, algumas indicações pertinentes que podem reduzir o prejuízo econômico e o conflito gerado pela predação por onças:

a) Manter os bezerros nos pastos mais distantes dos fragmentos florestais e das matas ciliares onde há maior incidência de predações por onças;

b) Concentrar o período de nascimento de bezerros em igual época do ano nas diferentes fazendas, para minimizar o impacto causado pelas onças;

c) Estudar a biologia e a ecologia das onças e de suas presas, realizando-se estimativas da disponibilidade de biomassa das presas silvestres;

d) Reduzir a caça predatória de presas silvestres potenciais às onças, especialmente nas áreas com maior incidência de predação;

e) Evitar o desmatamento e realizar projetos florestais para recuperar as áreas com maior incidência de predação;

f) Capacitar os técnicos que visitam regularmente as fazendas para a identificação, o registro e o controle da predação causada por predadores silvestres; 
g) Realizar planos de manejo participativos e educação ambiental com a população local, com agentes governamentais e não-governamentais, com as empresas privadas, entre outros;

h) Descontar os prejuízos econômicos causados pela predação no Imposto Territorial Rural (ITR) das propriedades rurais que a denunciarem aos órgãos competentes e que comprovarem perdas de rebanhos domésticos por onças;

i) Adequar as atuais políticas públicas ambientais e propor projetos de leis, visando incentivar os proprietários rurais que comprovem a presença de onças em suas terras.

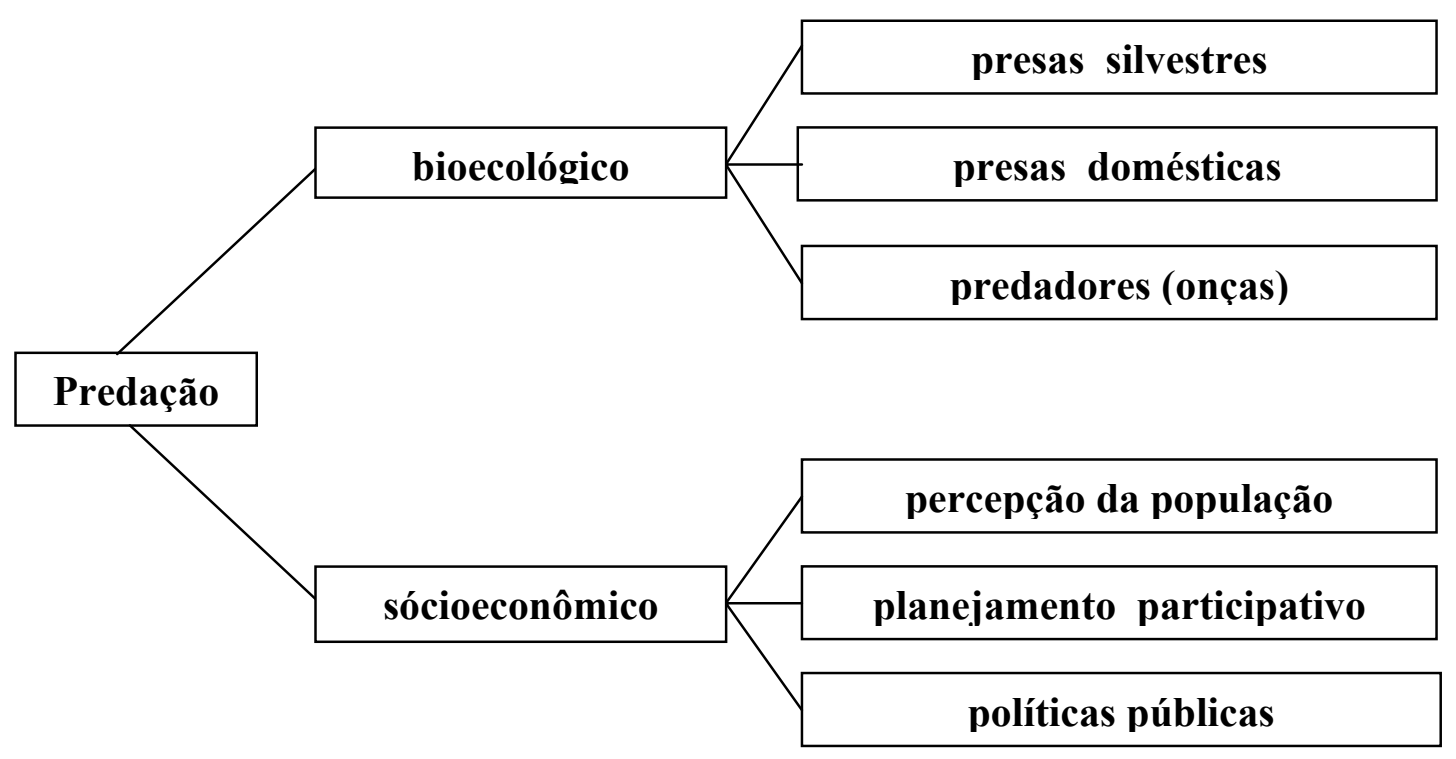

Figura 13 - Interação entre os aspectos bioecológicos e sócioeconômicos, necessária para reduzir o conflito causado pela predação de bovinos por onças 


\section{CONCLUSÕES}

A predação foi influenciada pela categoria dos bovinos (idade e sexo) e pelo período de nascimentos de bezerros.

A predação não foi aleatória e se diferenciou espacialmente e temporalmente.

A maioria das predações incidiu sobre os bezerros, se restringiu a poucas áreas e variou durante o ano e entre os anos.

A predação foi relativamente baixa e resultou em poucos prejuízos econômicos, que teve um grande significado para o proprietário.

Independentemente da perda causada pela predação, o resultado sempre foi o extermínio do predador.

A estratégia de manejo indicada para minimizar os efeitos a predação deve ser específica para cada área estudada.

Conclui-se que não basta atender o proprietário rural que tem problemas com a predação de suas criações por onças, mas também visitá-lo com freqüência para verificar a reincidência da predação na propriedade, tomando-se as medidas apropriadas e acompanhando-se os resultados. 
ANEXOS 
ANEXO A:

Ficha de morte dos bovinos

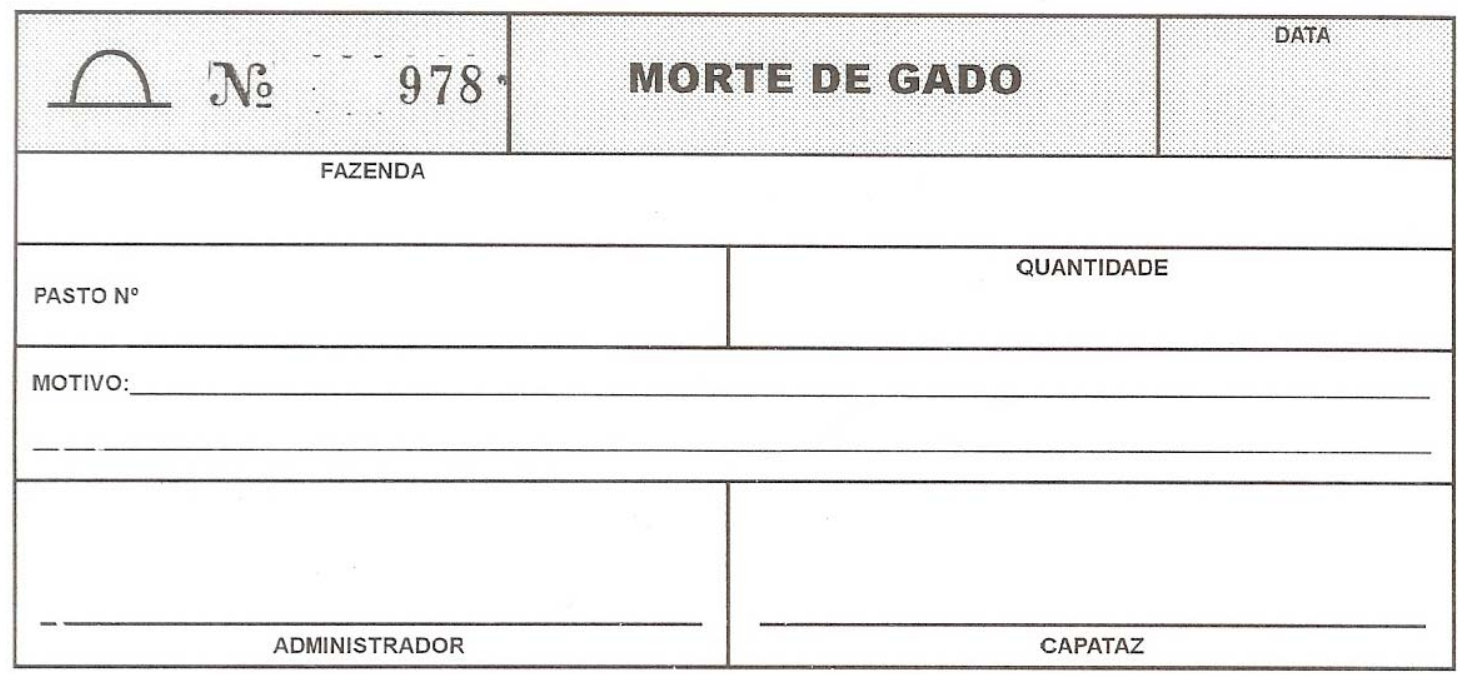


ANEXO B:

Bovinos predados por onças

Informante: __ Retiro: ___ Data: _ _ _ _ _ $\mathrm{n}^{\circ}$.

\begin{tabular}{|c|c|c|c|c|}
\hline Número $\left(\mathrm{n}^{\circ}\right)$ & Idade & Carimbo (mês) & Pasto $\left(n^{\circ}\right)$ & Data (mês/ano) \\
\hline & & & & \\
\hline & & & & \\
\hline & & & & \\
\hline & & & & \\
\hline & & & & \\
\hline & & & & \\
\hline & & & & \\
\hline & & & & \\
\hline & & & & \\
\hline & & & & \\
\hline & & & & \\
\hline & & & & \\
\hline & & & & \\
\hline & & & & \\
\hline & & & & \\
\hline & & & & \\
\hline & & & & \\
\hline & & & & \\
\hline & & & & \\
\hline & & & & \\
\hline & & & & \\
\hline & & & & \\
\hline
\end{tabular}


ANEXO C:

Boletim Pecuário

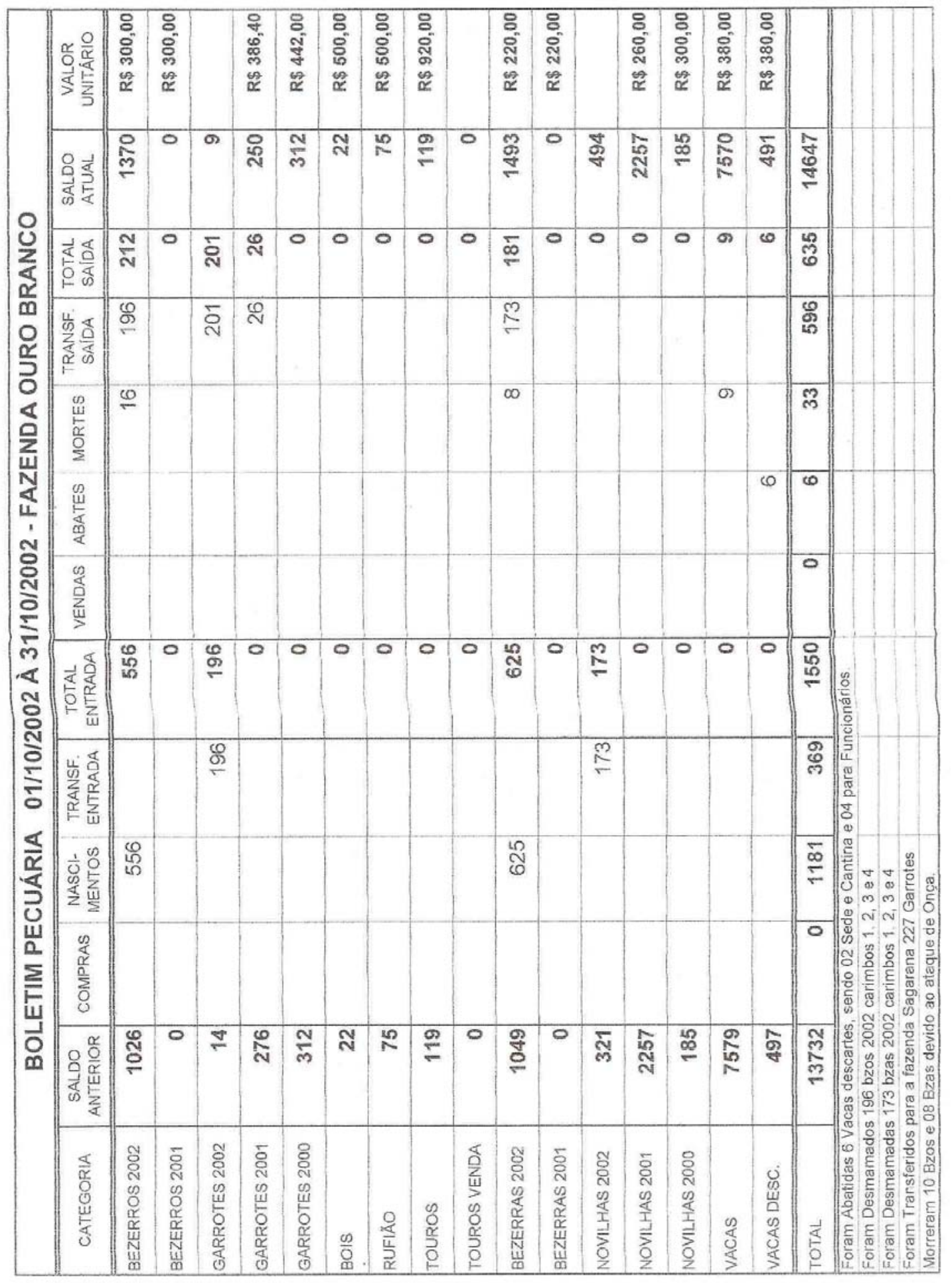


ANEXO D:

Chuvas (mm) de 1991 a 2003

\begin{tabular}{|c|c|c|c|c|c|c|c|c|c|c|c|c|c|}
\hline Dia & Jan & $\mathrm{Fev}$ & Mar & Abr & Mai & Jun & Jul & Ago & Set & Out & Nov & Dez & $(2003)$ \\
\hline 1 & 7 & & & 13 & & & & & & & 35 & 6 & \\
\hline 2 & 19 & & 35 & & & & & & & & & & \\
\hline 3 & 32 & & 30 & & & & & & & & 19 & & \\
\hline 4 & 40 & & & & & & & & & & 20 & & \\
\hline 5 & 77 & & & 15 & & & & & & & & 40 & \\
\hline 6 & & 13 & & 31 & & & & & & & & & \\
\hline 7 & & 20 & & & & & & & & & & & \\
\hline 8 & & & & 11 & & & & & & 7 & 16 & & \\
\hline 9 & & & 18 & & & & & & & & & 33 & \\
\hline 10 & & & 3 & & & & & & & & & & \\
\hline 11 & & & 60 & & & & & & & 22 & & 12 & \\
\hline 12 & 13 & 16 & 3 & & & & & & & & & & \\
\hline 13 & & & & 30 & & & & & & & & & \\
\hline 14 & & & 8 & & & & & & & & 40 & & \\
\hline 15 & & 17 & 55 & 25 & & & & & & & & & \\
\hline 16 & 23 & 7 & 38 & & & & & & & & 8 & & \\
\hline 17 & & 28 & & & & & & & & & 22 & & \\
\hline 18 & & 3 & & & & & & & & & & & \\
\hline 19 & 30 & 2 & & & & & & & & & 4 & & \\
\hline 20 & 6 & & & & & & & & 16 & & 5 & & \\
\hline 21 & 50 & 9 & & & & & & & & & & & \\
\hline 22 & 4 & & 10 & & & & & & & 8 & & & \\
\hline 23 & & 16 & & & & & & & & & & & \\
\hline 24 & & 2 & 10 & & & & & & & & 19 & & \\
\hline 25 & & & 20 & & & & & & & & & 20 & \\
\hline 26 & & & 4 & & & & & & & & & & \\
\hline 27 & & & & & & & & & & 29 & & & \\
\hline 28 & 10 & & & & & & & & & & & & \\
\hline 29 & 45 & & & & & & & & & 6 & & & \\
\hline 30 & 18 & & 43 & & & & & & & 12 & & & \\
\hline 31 & 27 & & & & & & & & 12 & & & & \\
\hline Total & 401 & 133 & 337 & 125 & 0 & 0 & 0 & 0 & 28 & 84 & 188 & 111 & Total \\
\hline 2002 & 826 & 198 & 172 & 22 & 5 & 0 & 0 & 0 & 30 & 133 & 286 & 305 & 1977 \\
\hline 2001 & 209 & 102 & 232 & 107 & 49 & 0 & 0 & 0 & 81 & 223 & 316 & 291 & 1610 \\
\hline 2000 & 505 & 430 & 543 & 189 & 0 & 0 & 0 & 0 & 54 & 165 & 590 & 411 & 2887 \\
\hline 1999 & 160 & 137 & 459 & 6 & 30 & 0 & 0 & 0 & 92 & 243 & 443 & 619 & 2189 \\
\hline 1998 & 243 & 335 & 202 & 44 & 6 & 0 & 0 & 0 & 46 & 261 & 206 & 212 & 1555 \\
\hline 1997 & 482 & 230 & 625 & 160 & 10 & 7 & 0 & 0 & 50 & 65 & 210 & 378 & 2217 \\
\hline 1996 & 100 & 340 & 295 & 248 & 100 & 0 & 0 & 34 & 19 & 71 & 155 & 172 & 1534 \\
\hline 1995 & 220 & 346 & 234 & 249 & 131 & 0 & 0 & 0 & 0 & 163 & 204 & 176 & 1723 \\
\hline 1994 & 250 & 142 & 272 & 82 & 8 & 30 & 0 & 0 & 0 & 29 & 282 & 401 & 1496 \\
\hline 1993 & 79 & 358 & 150 & 69 & 37 & 0 & 0 & 2 & 34 & 63 & 198 & 355 & 1345 \\
\hline 1992 & 575 & 466 & 176 & 35 & 50 & 0 & 0 & 0 & 83 & 132 & 232 & 380 & 2129 \\
\hline 1991 & 503 & 180 & 412 & 96 & 2 & 0 & 0 & 0 & 38 & 81 & 300 & 214 & 1826 \\
\hline Média & 346 & 272 & 314 & 109 & 36 & 3 & 0 & 3 & 44 & 136 & 285 & 326 & 1874 \\
\hline
\end{tabular}




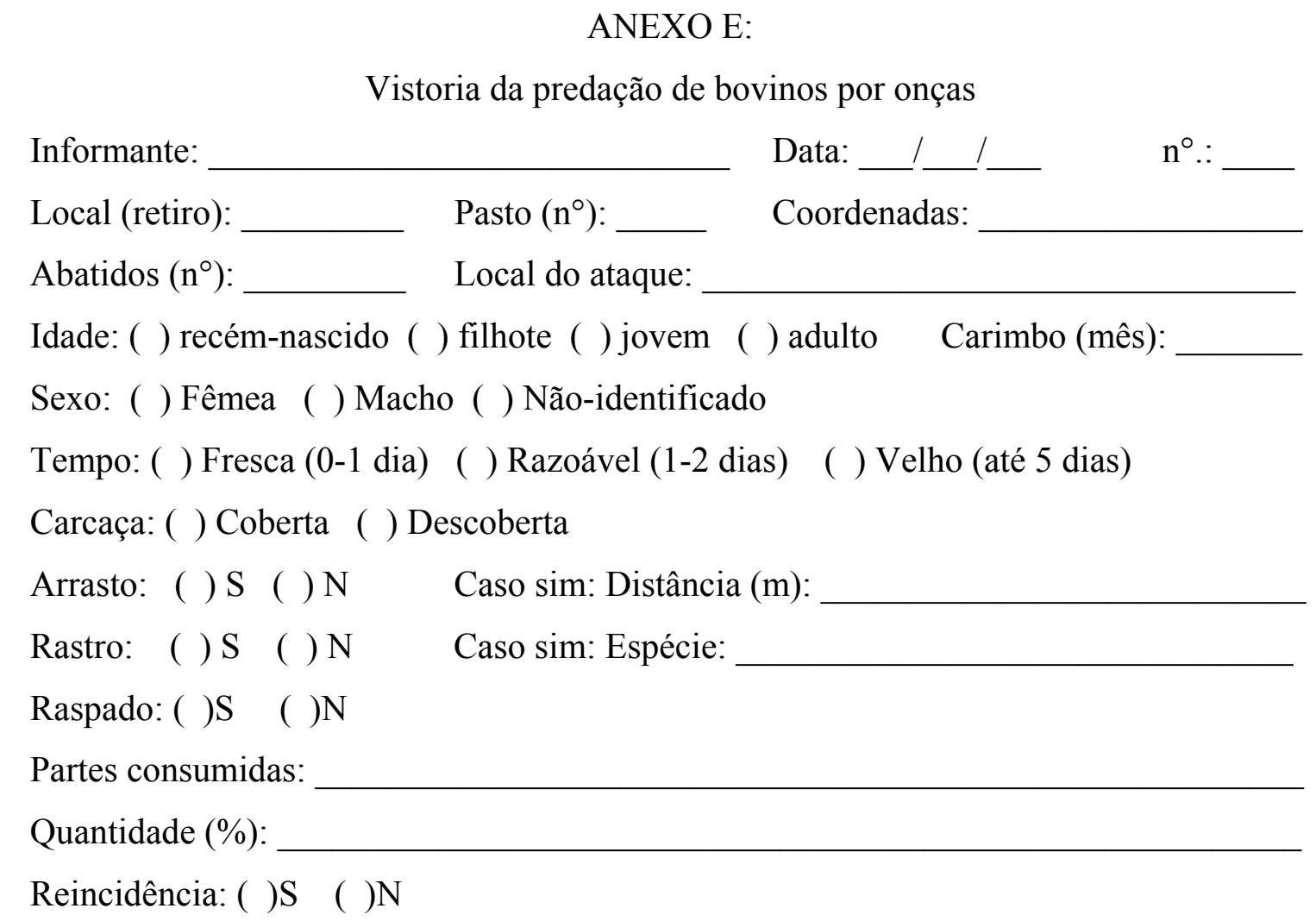




\section{REFERÊNCIAS BIBLIOGRÁFICAS}

ACKERMAN, B.B.; LINDZEY, F.G.; HEMKER, T.P. Cougar food habitats in southern Utah. Journal Wildlife Management, v.48, p.147-155, 1984.

ANDERSON, J.L. The re-estabilishment and management of a lion Panthera leo population in Zululand, South Africa. Biological Conservation, v.19, p.107-117, 1981.

AYRES, M.; AYRES JUNIOR, M.; AYRES, D.L.; SANTOS, A.S. BioEstat 2.0: aplicações estatísticas nas áreas das ciências biológicas e médicas. Belém: Sociedade Civil Mamirauá; Brasília: CNPQ, 2000. 272p.

CARVALHO, J.C.M.; LIMA, P.E.; GALVÃO, E. Observações zoológicas e antropológicas na região dos formadores do Xingu. Publicações Avulsas Museu Nacional Rio de Janeiro, v.5, p.1-49, 1949.

CENTENO, A.J. Curso de estatística aplicada à biologia. 2.ed. Goiânia: Editora da Universidade Federal de Goiás, 2000. 234p.

CENTRO NACIONAL DE PESQUISA PARA A CONSERVAÇÃO DE PREDADORES NATURAIS (CENAP). Manual de identificação, prevenção e controle de predação por carnívoros silvestres. Brasília: CENAP/IBAMA/Associação pró-carnívoros, 1998. 62p. 
CHILDS, J.L. Tracking the felids of the borderlands. El Paso: Corner Press, 1998. $77 \mathrm{p}$.

CHINCHILLA, F.A. La dieta del jaguar (Panthera onca), el puma (Felis concolor) y el manigordo (Felis pardalis) (Carnivora: Felidae) en el Parque Nacional Corcovado, Costa Rica. Revista de Biologia Tropical, v.45, p.1223-1229, 1997.

CONFORTI, V.L.; AZEVEDO, F.C.C. Local perceptions of jaguars (Panthera onca) and pumas (Puma concolor) in the Iguaçu National Park area, south Brazil. Biological Conservation, v.111, p.215-221, 2003.

CRAWSHAW JUNIOR, P.G. Recommendations for study densing on research projects on neotropical felids. In: Anonymous (Ed.). Felinos de Venezuela: biología, ecología e conservacíon. Caracas: FUDECI, 1992. p.187-222.

CRAWSHAW JUNIOR., P.G. Comparative ecology of ocelot (Felis pardalis) and jaguar (Panthera onca) in a protect subtropical forest in Brazil and Argentina. Florida, 1995. 190p. Thesis (Ph.D.) - University of Florida.

CRAWSHAW JUNIOR, P.G.; QUIGLEY, H.B. A ecologia do jaguar ou onça-pintada no Pantanal: estudos bioecológicos no Pantanal, parte I. Brasília: Instituto Brasileiro de Desenvolvimento Florestal (IBDF), 1984. 69p.

DINERSTEIN, E.; OLSON, D.M.; GRAHAM, D.J.; WEBSTER, A.L.; PRIMM, S.A.; BOOKBINDER, M.P.; LEDEC, G. A conservation assessment of the terrestrial ecorregions of Latin America and the Caribbean. Washington: The World Bank, 1995. 1v.

EMMONS, L.E. Comparative feeding ecology of felid in a neotropical rainforest. Behavioral Ecology and Sociobiology, v.20, p.271-283, 1987. 
FERRAZ, K.M.P.M.B.; LECHEVALIER, M.; COUTO, H.T.Z.; VERDADE, L.M. Damage caused by capybaras in a corn field. Scientia Agricola, v.60, p.191-194, 2003.

FONSECA, G.A.B.; RYLANDS, A.B.; COSTA, C.M.R.; MACHADO, R.B.; LEITE, Y. Livro vermelho dos mamíferos brasileiros ameaçados de extinção. Belo Horizonte: Fundação Biodiversistas, 1994. 459p.

FRANKLIN, W.L.; JOHNSON, W.E.; SARNO, R.J.; IRIARTE, J.A. Ecology of the Patagonia puma Felis concolor patagonica in southern Chile. Biological Conservation, v.90, p.33-40, 1999.

GARLA, R.; SETZ, E.Z.F.; GOBBI, N. Jaguar (Panthera onca) food habits in Atlantic rainforest of southeastern Brazil. Biotropica, v.33, p.691-696, 2001.

GUIX, J.C. El jaguar en la pluvisilva atlántica de Brasil. Vida Silvestre, v.7, p.32-37, 1992.

GUIX, J.C. Cat communities in six areas of the state of São Paulo, southeastern Brazil, with observations on their feeding habitats. Grupo de Estudos Ecológicos, Série Documentos, v.5, p.16-38, 1997.

HEMSON, G. The ecology and conservation of lions: human-wildlife conflict in semiarid Botswana. 2003. 213p. Thesis (Ph.D.) - University of Oxford.

HOOGESTEIJN, R.; HOOGESTEIJN, A.; MONDOLFI, E. Jaguar predation vs. conservation: cattle mortality by felines on three ranches in the Venezuelan Ilanos. In: DUNSTONE, N.; GORMAN, M.L. (Ed.). Mammals as predators, Proceeding Symposium Zoological Society of London, v.65, p.391-407, 1993. 
HOOGESTEINJ, R.; CHAPMAN, C.A. Large ranches as conservation tools in the Venezuelan Ilanos. Oryx, v.31, p.274-284, 1997.

INSTITUTO BRASILEIRO DE GEOGRAFIA E ESTATÍSTICA (IBGE). Malha Municipal, Brasília, 1997. 1v.

INSTITUTO BRASILEIRO DE GEOGRAFIA E ESTATÍSTICA (IBGE). Censo Demográfico, Brasília, 2000. 1v.

INSTITUTO BRASILEIRO DE GEOGRAFIA E ESTATÍSTICA (IBGE). Mapas de Solos do Brasil, Brasília, 2001. 1v.

INSTITUTO BRASILEIRO DE GEOGRAFIA E ESTATÍSTICA (IBGE). Mapa da Série Brasil Geográfico. 2.ed., Brasília, 2002. 1v.

IRIARTE, J.A.; FRANKLIN, W.L.; JOHNSON, W.E.; REDFORD, K.H. Biogeographic variation of food habits and body size of the America puma. Oecologia, v.85, p.185-190, 1990.

JACKSON, P.; NOWELL, K. Problems and possible solutions in management of felid predators. Journal Wildlife Research, v.1, p.304-314, 1996.

JACKSON, R.; WANG, R. Linking snow leopard conservation and people-wildlife conflict resolution: grassroots measures to protect the endangered snow leopard from herder retribution. Endangered Species UPDATE, v.18, p.138-141, 2001.

LAUNDRÉ, J.; CLARK, T.W. Managing puma hunting in the western United States: through a metapopulation approach. Animal Conservation, v.6, p.159-170, 2003. 
LEITE, M.R.P. Relações entre a onça-pintada, onça-parda e moradores locais em três unidades de conservação da Floresta Atlântica do estado do Paraná, Brasil. Curitiba, 2000. 72p. Dissertação (Mestrado) - Universidade Federal do Paraná.

LEITE, M.R.P.; CRAWSHAW JUNIOR, P.G. Toizinho e a onça. São Paulo: Editora LAKE, 1999. 14p.

LINNELL, J.D.C.; AANES, R.; SWENSON, J.E.; ODDEN, J.; SMITH, M.E. Translocation of carnivores as a method for managing problem animals: a review. Biodiversity and Conservation, v.6, p.1245-1257, 1997.

LINNELL, J.D.C.; ODDEN, J.; SMITH, M.E.; AANES, R.; SWENSON, J.E. Large carnivores that kill livestock: do "problem individuals" really exist? Wildlife Society Bulletin, v.27, p.698-705, 1999.

MÄHLER JUNIOR, J.K.F. Avaliação dos danos causados por ungulados silvestres (Mammalia: Artiodactyla e Perissodactyla) nas propriedades limítrofes ao Parque Estadual do Turvo como instrumento de manejo e conservação. In: CONGRESSO BRASILEIRO DE UNIDADES DE CONSERVAÇÃO, 2., Campo Grande, 2000. Anais. Campo Grande: Rede Nacional Pró-Unidades de Conservação/Fundação O Boticário à Natureza, 2000. v.2, p.168-177.

MANZATTI, L. Predação de animais domésticos e plantações no entorno do Parque Nacional do Iguaçú (PR) - Análise da percepção de fazendeiros e alternativas de manejo. Piracicaba, 1999. 81p. Dissertação (Mestrado) - Escola Superior de Agricultura “Luiz de Queiroz”, Universidade de São Paulo. 
MARQUES, S.R. Levantamento preliminar de denúncias de ataques por felídeos de grande porte no entorno da Estação Ecológica Serra das Araras. Cuiabá, 1999. 45p. Monografia (Graduação) - Instituto de Biociências, Universidade Federal de Mato Grosso.

MAZZOLLI, M. Ocorrência de Puma concolor (LINNAEUS) (FELIDAE, CARNIVORA) em áreas de vegetação remanescente de Santa Catarina, Brasil. Revista Brasileira de Zoologia, v.10, p.581-587, 1993.

MAZZOLLI, M.; RYAN, C. B.; GRAIPEL, M. Effects and patterns of mountain lion (Puma concolor LINNAEUS) (FELIDAE, CARNIVORA) predation of livestock on small and medium sized properties in Santa Catarina, Brazil. MOUNTAIN LION WORKSHOP, 5., San Diego, 1996. Proceedings. San Diego: s.ed. 1996. 1v.

MAZZOLLI, M.; GRAIPEL, M.E.; DUNSTONE, N. Mountain lion depredation in southern Brazil. Biological Conservation, v.105, p.43-51, 2002.

MINISTÉRIO DO MEIO AMBIENTE. Lei da vida: a lei dos crimes ambientais. Lei ${ }^{\circ}$. 9.605 de 12 de fevereiro de 1998 e Decreto $n^{\circ} 3.179$ de 21 de outubro de 1999. Brasília, 2000. 38p.

MIRANDA, E.E.; GUIMARÃES, M. GeoGoiás 2002: Mapa da cobertura vegetal do Estado. Brasília, 2002. 1v.

MITTERMEIER, R.A.; MYERS, N.; GIL, P.R.; MITTERMEIER, C.G. Hots Pots: earth's biologically richest and most endangered terrestrial ecorregions. Mexico City: CEMEX/Conservation International, 1999. 430p. 
MIZUTANI, F. Home range of leopards and their impact on livestock on Kenya ranches. In: DUNSTONE, N.; GORMAN, M.L. (Ed.). Mammals as predators, Proceeding Symposium Zoological Society of London, v.65, p.425-439, 1993.

MONDOLFI, E.; HOOGESTEIJN, R. Notes on the biology and status of the jaguar in Venezuela. In: MILLER, S.D.; EVERETT, D.D. (Ed.). Cats of the world: biology, conservation and management. Washington: National Wildlife Federation, 1986. p.125-146.

NOWELL, K.; JACKSON, P. Wild cats: status survey and conservation action plan. Gland: International Union for Conservation/Natural Resources, 1996. 382p.

NOVACK, A.J. Impacts of subsistence hunting on the foraging ecology of jaguar and puma in the Maya Biosphere Reserve, Guatemala. Florida, 2003. 38p. Thesis (M.S.) - University of Florida.

NÚÑEZ, R.; MILLER, B.; LINDZEY, F. Food habits of jaguar and pumas in Jalisco, Mexico. Journal of Zoology, London, v.252, p.373-379, 2000.

OLI, M.K.; TAYLOR, I.R.; RODGERS, M.E. Snow leopard Panthera uncia predation of livestock: an assessment of local perceptions in the Annapurna Conservation Area, Nepal. Biological Conservation, v.68, p.63-68, 1994.

PATTERSON, B.D.; KASIKI, S.M.; SELEMPO, E.; KAYS, R.W. Livestock predation by lions (Panthera leo) and others carnivores on ranches neighboring Tsavo National Parks, Kenya. Biological Conservation, v.119, p.507-516, 2004.

PEROVIC, P.G.; HERRÁN, M. Distribución del jaguar Panthera onca en las Provincias de Jujuy y Salta, Noroeste de Argentina. Mastozoología Neotropical, v.5, p.47-52, 1998. 
PITMAN, M.R.P.L.; OLIVEIRA, T.G.; CAVALCANTI, S.M.C.; PAULA, R.C.; INDRUSIAK, C. Manual de identificação, prevenção e controle de predação por carnívoros. Brasília: Edições IBAMA, 2002. 83p.

POLISAR, J.; MATIX, I.; SCOGNAMILLO, D.; FARRELL, L.; SUNQUIST, M.E.; EISENBERG, J.F. Jaguars, pumas, their prey base, and cattle ranching: ecological interpretations of a management problem. Biological Conservation, v.109, p.297$310,2003$.

QUIGLEY, H.B.; SCHALLER, G.B.; CRAWSHAW JUNIOR, P.G. Ecology and conservation of the jaguar in the Pantanal region of Brazil. Final Report to National Geographic Society. Brasília, 1988. 1v.

QUIGLEY, H.B.; CRAWSHAW JUNIOR, P.G. A conservation plan for the jaguar (Panthera onca) in the Pantanal region of Brazil. Biological Conservation, v.61, p.149-157, 1992.

RABINOWITZ, A.R. Jaguar predation on domestic livestock in Belize. Wildlife Society Bulletin, v.14, p.170-174, 1986.

RABINOWITZ, A.R.; NOTTINGHAM, B.G. Ecology and behaviour of the jaguar (Panthera onca) in Belize, Central America. Journal of Zoology, London, v.210, p.149-159, 1986.

RAU, J.R.; JIMÉNEZ, J.E. 2002. Diet of puma (Puma concolor, Carnivore: Filed) in Coastal and Andean Ranges of Southern Chile. Studies on Neotropical Fauna and Environment, v.37, p.201-205, 2002. 
RYLANDS, A.B.; SILVA, J.A.S.; CALAÇA, P.F.; SÁBATO, M.A..L.; OLIVEIRA, L.C. Monitoramento de felinos predadores de animais domésticos no Estado de Minas Gerais, com ênfase no Vale do Rio Doce. Belo Horizonte: 1995. 46p. (Relatório apresentado ao Instituto Estadual de Florestas; Universidade Federal de Minas Gerais).

SANDERSON, E.W.; CHETKIEWICZ, C.L.B.; RABINOWITZ, A.; REDFORD, K.H.; ROBINSON, J.G.; TABER, AB A geographic analysis of the status and distribution of jaguars across the range. In: MEDELLIN, R.A.; CHETKIEWICZ, C.L.B.; RABINOWITZ, A.; REDFORD, K.H.; ROBINSON, J.G.; SANDERSON, E.W.; TABER, AB (Ed.). El jaguar en el nuevo milenio. Una evaluacion de su estado, deteccion de prioridades y recomendaciones para la conservacion de los jaguares en America. Mexico: Universidad Nacional Autonoma de México/Wildlife Conservation Society, 1999. 300p.

SCHALLER, GB Mammals and their biomass on a Brazilian ranch. Arquivos de Zoologia, São Paulo, v.31, p.1-36, 1983.

SCHALLER, G.B.; CRAWSHAW JUNIOR, P.G. Movement patterns of jaguar. Biotropica, v.12, p.161-168, 1980.

SCHALlER, G.B.; JUNRANG, R.; MINGJIANG, Q. Status of the snow leopard Panthera uncia in Qinghai and Gansu Provinces, China. Biological Conservation, v.45, p.179-194, 1988.

SCOGNAMILlO, D.; MATIX, I.E.; SUNQUIST, M.; POLISAR, J. Coexistence of jaguar (Panthera onca) and puma (Puma concolor) in a mosaic landscape in the Venezuelan Ilanos. Journal of Zoology, London, v.259, p.269-279, 2003. 
SEIDENSTICKER, J.; MCDOUGAL, C. Tiger predatory behaviour, ecology and conservation. In: DUNSTONE, N.; GORMAN, M.L. (Ed.). Mammals as predators, Proceeding Symposium Zoological Society of London, v.65, p.105$125,1993$.

SICK, H. Ornitologia brasileira. 2.ed. Rio de Janeiro: Nova Fronteira, 1997. 912p.

SILVA, F. Mamíferos silvestres: Rio Grande do Sul. 2.ed. Porto Alegre: Fundação Zoobotânica do Rio Grande do Sul, 1994. 246p.

TABER, A.B.; NOVARO, A.J.; NERIS, N.; COLMAN, F.H. The food habitats of sympatric jaguar and puma in the Paraguayan Chaco. Biotropica, v.29, p.204-213, 1997.

TERBORGH, J. The role of felid predators in neotropical forests. Vida Silvestre Neotropical, v.2, p.3-5, 1990.

VERDADE, L.M.; CAMPOS, C.B. How much is a puma worth? Economic compensation as an alternative for the conflict between wildlife conservation and livestock production in Brazil. Biota Neotropica, v.4, p.1-4, 2004.

YÁÑEZ, J.L.; CÁRDENAS, J.C.; GEZELLE, P.; JAKSIC, F.M. Food habits of the southernmost mountain lions (Felis concolor) in South America: natural versus livestock ranges. Journal of Mammalogy, v.67, p.604-606, 1986.

ZIMMERMANN, A. Jaguar rancher conflict in the north Pantanal of Brazil. Kent, 2000. 5p. Dissertation (M.S.) - Durrell Institute of Conservation and Ecology, University of Kent (Summary). 